\title{
Learning to Prepare Hauling Systems for Rope Rescue
}

by (C) Brenna McWilliams

A Thesis submitted to the

School of Graduate Studies

In partial fulfillment of the requirements for the degree of

Master of Science in Kinesiology

School of Human Kinetics and Recreation

Memorial University of Newfoundland

May 13, 2019

St. John's Newfoundland and Labrador 


\begin{abstract}
Introduction: While there is a good understanding of how anxiety impacts skill performance, we understand less about how anxiety affects the learning process. We attempted to create an environment that caused anxiety by having people practice the skill of preparing rope rescue hauling systems $(3: 1 \& 5: 1)$ at height. Methods: Participants were assigned to a Low practice group, that completed training in a general classroom setting; and a High practice group, that trained at a $14 \mathrm{~m}$ height. Retention tests, to assess learning, were completed one week after practice. All participants were tested on the hauling systems at an elevated height and in a classroom setting. A checklist of each element of the hauling systems was used to assess configuration performance error scores. Movement time (MT) of the preparation was recorded for each trial. Cognitive anxiety was examined through a Likert Scale delivered after each trial. Somatic anxiety was observed using a Zephyr Bioharness system, which measured heart rate (HR) and heart rate variability (HRV). Results: Configuration performance during practice was lower for the High practice group compared to the Low practice group. Perceived anxiety decreased with practice. During retention, which reflected learning, perceived anxiety was higher for the low practice location (classroom) compared to the high practice (elevated) testing location. MT was longest for the complex 5:1 system when performing at height. Conclusion: The current study is one of the first studies to assess rope rescue skills and anxiety induced by different complexities and environments. Performance at height, when there are cognitive challenges (the difficulty associated with completing the 5:1 system) is impaired. However, training at height does not appear to influence this effect. As well, trainees should practice all complexities or specific skills that need to be learned multiple times.
\end{abstract}

Key words: task complexity, anxiety, performance, environment, training, rope rescue 


\section{ACKNOWLEDGEMENTS}

First, I would like to thank my supervisors, Dr. Linda Rohr and Dr. Heather Carnahan, for offering me this amazing chance to work with them as I pursue my Masters degree here at Memorial University. You both have shown me what hard work can amount to. Your strength and kindness are substantial inspirations for me and I could not have chosen better professors to work with. I cannot thank you two enough.

I would like to thank my family and friends. I would not be where I am today without any of you. My Masters experience has been a roller coaster of emotions and I feel so fortunate that I had such strong support through all of it.

To all the administrative personel and instructors from Memorial University and Marine Institute, I thank you for welcoming me into the community and providing so much support. In particular, I would like to thank, Dr. Elizabeth Sanli and Dan LaCour for all the assistance through my project. I would also like to thank everyone that has worked in the Ocean Safety lab that has helped me along the way.

Lastly, I would like to thank, Travis. You have been my biggest supporter and I can't thank you enough for everything you do. I could not have done this without you. 


\section{TABLE OF CONTENTS}

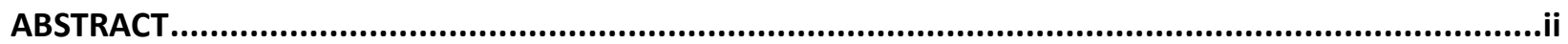

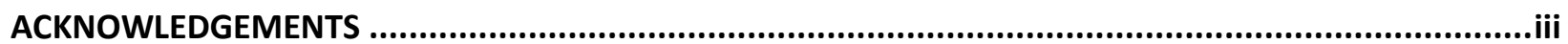

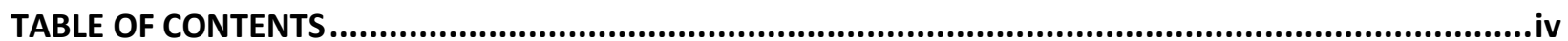

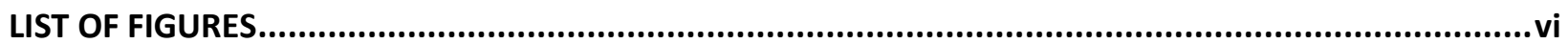

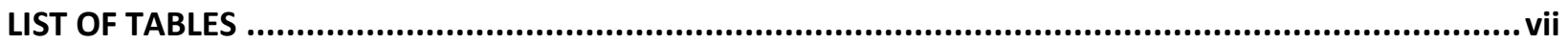

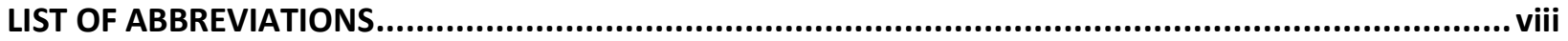

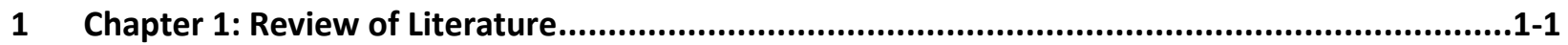

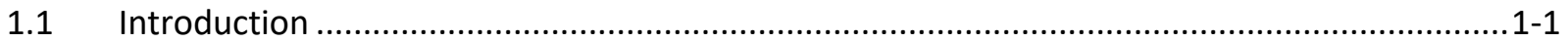

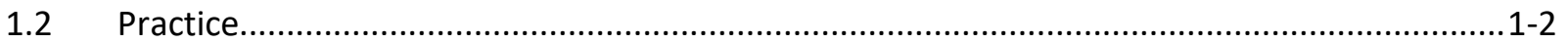

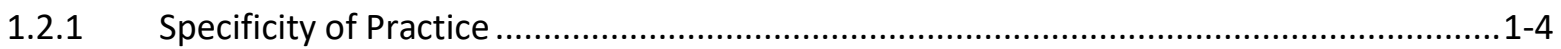

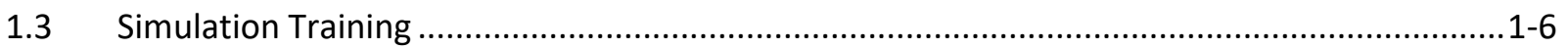

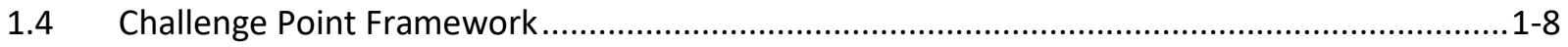

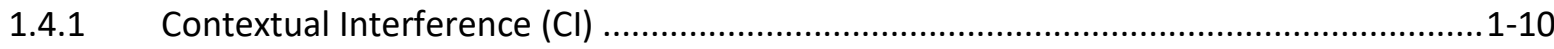

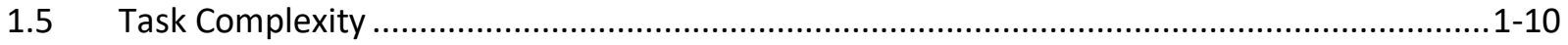

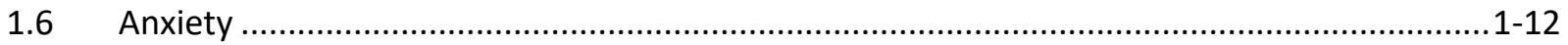

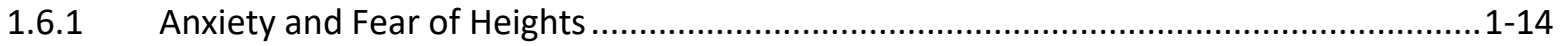

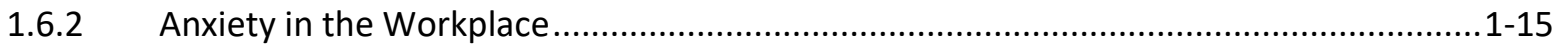

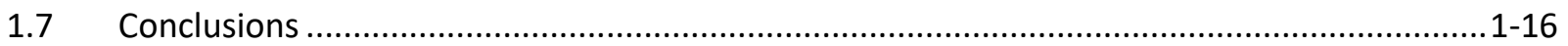

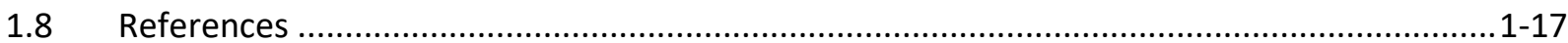

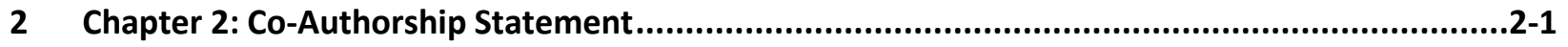

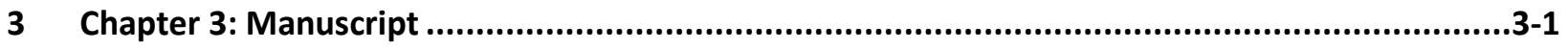

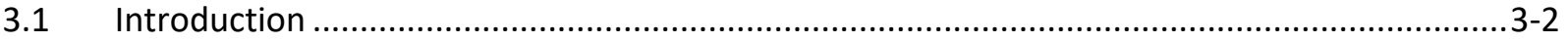

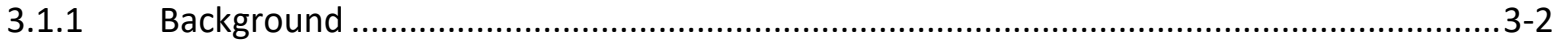

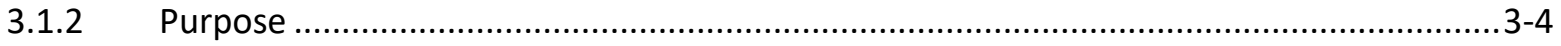

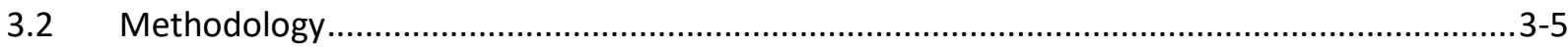

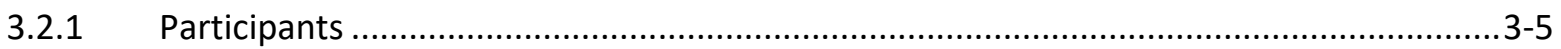

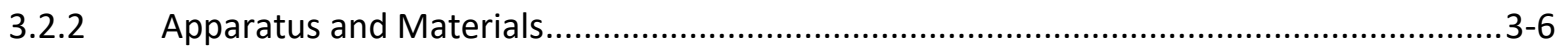

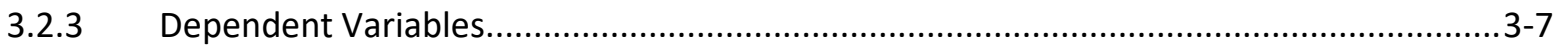

3.2.4 Procedure

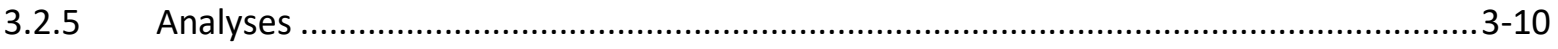

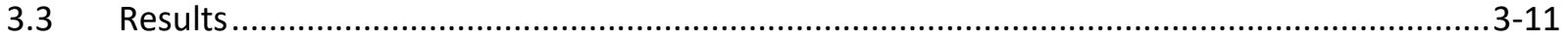

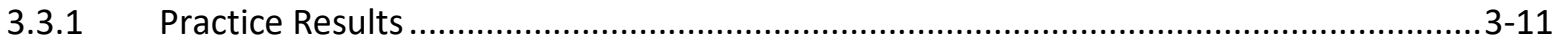




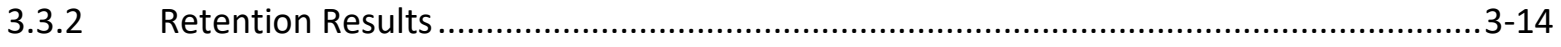

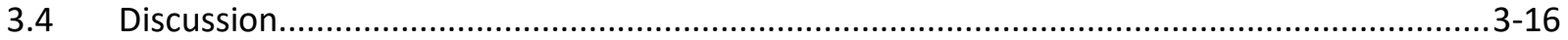

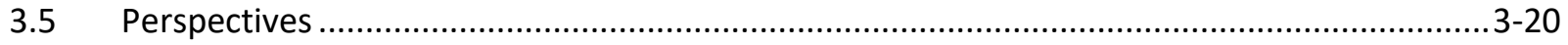

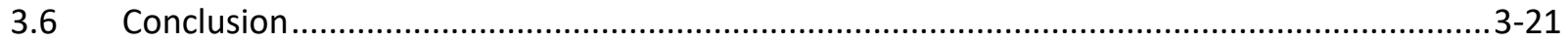

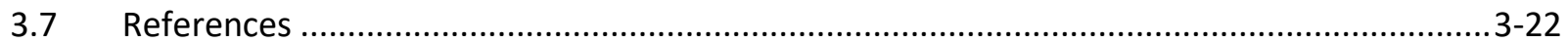

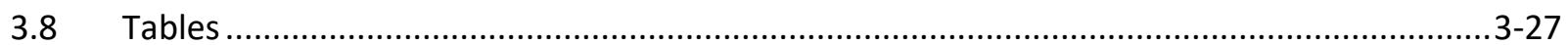

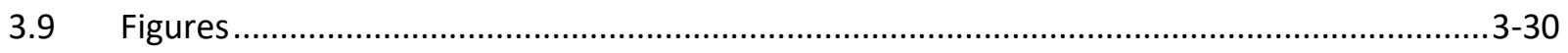




\section{LIST OF FIGURES}

Figure 1. 3:1 and 5:1 hauling systems..................................... 30

Figure 2. Configuration checklist for the $3: 1$ condition............................ 31

Figure 3. Illustration of the procedures based on the day .......................... 32

Figure 4. Dependent variables during aqcuisition training graphs................... 33
A. The average configuration score based on practice group.
B. Movement time (MT) based on practice trial.

Figure 5. The average configuration scores of each practice trial. $3-34$

Figure 6. Perceived anxiety scores during each complexity and each practice trial.....3 - 35

Figure 7. The average Heart Rate during each complexity and each practice trial.......3 - 36

Figure 8. Dependant variables during retention testing. $3-37$
A. The average perceived anxiety levels of each retention testing location.
B. The perceived anxiety of each group while completing both complexities.
C. The Movement time (MT) (seconds) based on task complexity and location. 


\section{LIST OF TABLES}

Table 1. Significant main effects and interactions................................. 27
A. for practice.
B. for retention.

Table 2. Absolute data of mean and standard error values............................... $3-28$
A. during practice.
B. during retention. 


\section{LIST OF ABBREVIATIONS}

\begin{tabular}{|c|c|}
\hline ANOVA & Analysis of Variance \\
\hline bpm & Beats Per Minute \\
\hline $\mathrm{CI}$ & Contextual Interference \\
\hline EI & Emotional Intelligence \\
\hline $\mathrm{g}$ & grams \\
\hline HR & Heart Rate \\
\hline HRV & Heart Rate Variability \\
\hline M & Mean \\
\hline $\mathrm{m}$ & meter \\
\hline $\mathrm{mm}$ & millimeter \\
\hline $\mathrm{ms}$ & millisecond \\
\hline MT & Movement Time \\
\hline $\mathrm{NIH}$ & National Institute of Health \\
\hline $\mathrm{SD}$ & Standard Deviation \\
\hline STAI & State-Trait Anxiety Inventory \\
\hline sec & seconds \\
\hline
\end{tabular}




\section{Chapter 1: Review of Literature}

\subsection{Introduction}

Learning is an activity that humans participate in from birth to death. As human beings, our lives are based on learning new skills and advancing existing skills. The skills that humans can learn seem to have an endless capacity. Motor learning is defined by Magill as, "the change in the capability of a person to perform a skill that is inferred from practice or experience and is relatively permanent" (2004, p. 134). Some skills can be learned implicitly, which is the unconscious learning of a skill (Wulf \& Schmidt, 1997). However, typically to learn a skill, practice is required. Practice is the deliberate repetition of a skill, and it is generally the most important part of improving and mastering skills (Adams, 1964; Guadagnoli \& Lee, 2004; Magill, 2001; Schmidt \& Lee, 2018). Many factors influence the quality of motor learning; for example, feedback (e.g. Badets \& Blandin, 2012), simulation environments (e.g. Walsh, Rose, Dubrowski, Ling, Grierson, Backstein \& Carnahan, 2011), stress and anxiety (e.g. Young, St, Gibson, Partington, Partington, \& Wetherell, 2013), the amount of practice (e.g. Guadagnoli \& Lee, 2004), the type and difficulty of skill (e.g. Wulf \& Shea, 2002), and the applicability of a practice skill to real life (e.g. Wrisberg \& Liu,1991). Although many of these factors are well studied, some elements like anxiety and task complexity in motor learning require further study (e.g. Adams, 1964; Guadagnoli \& Lee, 2004; Magill, 2001; Maran \& Glavin, 2003; Mori, Carnahan, \& Herold, 2015; Schmidt \& Lee, 2018; Walsh et al., 2011; Wulf \& Shea, 2002; Young et al., 2013). The properties and fundamental concepts of motor learning and performance are relevant to the life and work of many individuals.

To examine motor learning, researchers typically observe performance, but performance is not considered motor learning. Since motor learning is immeasurable, performance measures are used to indicate and reflect the learning of a skill. Performance is described as, "the behavioural 
act of executing a skill at a specific time and in a specific situation" (Magill, 2004, p.193). Typically, improvements in performance indicate skill learning (Luft \& Buitrago, 2005). Performance can be measured in many ways; for example, reaction time (Henry \& Rogers, 1964; Klapp, 1995; Magill, 2004, p.20), error measures (Magill, 2004, p.23; Schmidt, Zelaznik, Hawkins, Frank, \& Quinn, 1979), and kinetics and kinematics (Magill, 2004, p.29). These dependent measures can be used to evaluate performance over multiple trials to create learning curves (Crossman, 1959). To measure performance and skill learning over a period of time researchers use retention and transfer testing to examine these effects. Retention tests are, "tests of a practiced skill that a learner performs following an interval of time after practice has ceased" (Magill, 2004, p.199). While transfer tests are, "tests in which a person performs a skill that is different from the skill he or she practiced or performs the practiced skill in a context or situation that is different from the practice context or situation" (Magill, 2004, p.201). Retention and transfer tests are a valid predictor of learning and many researchers have utilized these tests (e.g. Guadagnoli \& Lee, 2004; Jarus \& Gutman, 2001; Porte et al., 2007; Wrisberg \& Lui, 1991; Wulf $\&$ Shea, 2002). While many factors influence the outcome of performance and motor learning, it is important to have an understanding of these factors to improve skills.

\subsection{Practice}

One of the most important factors that effectively demonstrates improvements in motor learning, is practice (Adams, 1964; Guadagnoli \& Lee, 2004; Magill, 2001; Schmidt \& Lee, 2018). Repetition of certain skills under a variety of conditions can allow an individual to learn a skill and develop into an expert. Although the amount of practice has generally been positively related to skill improvement, many factors also contribute to whether practice will be beneficial or not. Some

of these factors include feedback (e.g. Badets \& Blandin, 2012), the type and difficulty of skill 
(e.g. Wulf \& Shea, 2002), and the generalizability (e.g. Wrisberg \& Liu,1991) and environment of the practice setting. Practice can be performed in a controlled laboratory/classroom setting or in a real-world field setting. Collectively, these variables influence the rate and degree of skill learning.

Individuals can use both mental and physical practice to improve motor skill learning. One of the functions of mental practice is that it assists the performer in psychologically preparing to perform a skill (Feltz \& Landers, 1983). Research has shown that mental practice can enhance teamwork and technical skills, especially in high fidelity simulations (Arora, Aggarwal, Hull, Miskovic, Kneebone, Darzi \& Sevdalis, 2011). Mental practice has been proposed to be a time and cost-effective strategy to enhance training (Arora et al., 2011). Both mental and physical practice were found to be equally effective during acquisition of skill development (Stebbins, 1968). For example, Brouziyne and Molinaro (2005) observed that a combination of mental and physical practice can benefit beginners performance of golf shots. Therefore, to increase an individual's performance and learning, mental practice should be added so that the full benefit from physical practice can be realized.

The relationship between practice and skill learning is often referred to as a law of practice (Newell \& Rosenbloom, 1981) and mathematical models have largely represented this statement (Crossman 1959; Guadagnoli \& Lee, 2004). The National Institute of Health (NIH, 2009) describe five steps of a skill proficiency scale; fundamental awareness, novice, intermediate, advanced, and expert. Fundamental awareness is the first step in skill learning and where knowledge and understanding of the basic techniques or concepts is learned. Novices can discuss terminology, concepts, principles and issues then utilize all the resource materials in this competency; these individuals typically need assistance completing the skill. Individuals with intermediate and advanced proficiencies can independently perform the skills. Experts have the recognized 
authority and the ability to provide guidance, assistance with troubleshooting and answer questions related to this area (NIH, 2009). Experts achieve skill mastery after many years of practice, with researchers arguing that more than ten thousand hours of deliberate practice is needed to achieve mastery and expertise (Ericsson, Krampe \& Tesch-Römer, 1993; Gladwell, 2008). Guadagnoli and Lee (2004) state that, "if skill level is related positively to the development of skill at the task, then larger amounts of practice will produce learners of higher skill” (p.219). In practice, many factors can have negative impacts on skill performance. During practice different types of praise (Baumeister, Hutton, \& Cairns, 1990), training environments (Kozak, Hancock, Arthur \& Chrysler, 1993), and psychological factors (Hordacre, Immink, Ridding \& Hillier, 2016) can impact skill performance negatively. The task, environment, and individually specific properties of practice has very large impacts on the quality of motor learning and performance.

\subsubsection{Specificity of Practice}

To maximize learning and performance, it is best to provide specific training that reflects the real-world situation. The task, individual, and learning characteristics are factors that affect the specificity of training (Magill \& Hall, 1990). Context specificity refers to the environmental factors that influence remembering and learning of information (Schmidt \& Lee, 2018). These environmental factors can affect individuals physically and emotionally, thus affecting performance. For example, a cold environment (Parsons, 2014, p.396) can impair an individual physically; conditions that include an element of fear (Rodriguez, Craske, Mineka \& Hladek, 1999) can impact an individual emotionally, thus impacting performance and learning. The greatest benefits from performance can be achieved if the practice that is prescribed is specific to the desired outcomes and context (Minett \& Costello, 2015). A laboratory task has increased control but it can be less generalizable (Mook, 1983; Mori et al., 2015). In an occupation that has 
a certain element of anxiety, for example firefighting, the training should incorporate a certain level of anxiety while learning skills to fully maximize an individual's learning and performance. One approach that is used within training programs for anxious conditions is the concept of stress inoculation. Stress inoculation is described as training with effective coping skills prior to stress exposure to prepare the individual for future stressful events (Saunders, Driskell, Johnston \& Salas, 1996). This approach was originally used to assist individuals with phobias, pain and anger but researchers demonstrated it's use in workplace training to minimize anxiety and maximize performance. Saunders and colleagues (1996) observed that stress inoculation training reduced state anxiety while enhacing performance under anxious conditions. This provides evidence for the specificity of learning principle and practicing with anxiety.

The specificity of learning principle is described by Henry (1968) as the "best learning experiences are those which approximates most closely the movement components and environmental conditions of the target skill and context" (Schmidt \& Wrisberg, 2004, p.198). The two components of this principle have shown how context specificity (Smith, 1998) and task specificity (Linn \& Burton, 1994) can negatively impact performance and learning. Context specificity can have a large impact on performance and learning domain but these results can also be impacted by task specificity. The task specificity refers to whether the task being practiced is similar to the task that is meant to be learned. These tasks can range from simple to complex skills. Task difficulty is explained further below. For learning to be optimized for the individual, training needs to be multisensory to allow for individual learning needs (Shams \& Sietz, 2008). Some research pertaining to the specificity of training and learning focuses on how the source of afferent visual information needs to be specific for optimal performance and learning (Tremblay \& Proteau, 1998). This principle has been shown in manual aiming and positioning tasks (Proteau, 1992), 
precision walking (Proteau, Tremblay \& Dejaeger, 1998), and powerlifting (Tremblay \& Proteau, 1998) and indicates that the specificity of learning hypothesis applies to various types of tasks. To maximize the benefits of learning through practice, environmental, individual and task specific factors all need to be involved in training development (Lewthwaite \& Wulf, 2012).

\subsection{Simulation Training}

Motor skills can be learned in simulated environments and in applied settings. Simulation environments are important because they allow a degree of control and safety but they also allow the participant to practice in an environment that is more realistic than a classroom setting (Kneebone, 2009; Walsh et al., 2011). Simulation has been evolving for the last several centuries (Perkins, 2007) with evidence of the first involvement of medical field simulation developed by Abrahamson and Denson in the late 1960s (Bradley, 2006). Simulation training has many applications and is widely integrated into programs where skill learning is imperative, including healthcare, military, driving, air traffic control, first responder education, engineering, and public services contexts (e.g. Maran \& Glavin, 2003; Mori et al., 2015; Walsh et al., 2011; Yeung, Dubrowski, \& Carnahan, 2013; Young et al., 2013). Walsh and colleagues (2011) offer valid reasoning for integrating simulation training into procedural skill acquisition by explaining that students enhance, develop, and refine their skills through repetitive practice. Since simulations occur in a controlled environment, safety training can also be added as a benefit of simulation training (Kneebone, 2009). Another benefit includes the learner has multiple controlled practice attempts in a supportive and educational environment. In many cases, failure in simulation training is encouraged so students can review the experience and learn from their mistakes in a protected environment (Perkins, 2007). While simulation techniques are beginning to be used by many researchers as a factor in experimental design (e.g., Maran \& Glavin, 2003; Mori et al., 2015; 
Walsh et al., 2011; Yeung et al., 2013) further research needs to be performed to provide a better methodological base for simulation training (Bradley, 2006).

One concept that aligns with simulation training is simulation fidelity; which is, "the degree to which a model or simulation reproduces the state and behaviour of a real-world object, feature or condition" (Hays \& Singer, 1989, p.49). Low fidelity simulations are typically lower cost and are less like the real-world conditions; for example, classroom-based training for a skill that is never used in a classroom. High fidelity simulations include environments very similar to the realworld condition; for example, simulated patients in the medical environment (Maran \& Glavin, 2003). Norman, Dore and Grierson (2012) summarized how high-fidelity simulation provides gains in performance and transfer learning. McGaghie and colleagues (2006) discovered that there was a positive relationship between number of hours of high-fidelity simulation practice and standardized medical evaluations. Depending how representative the simulation is to the actual environment, the generalizability of the study can increase or decrease and this can be vital for research.

Simulation training can occur in both controlled environments as well as virtual spaces. In particular, firefighter training is often completed in virtual environments to minimize risk (Perdigau et al., 2003; St Julien, \& Shaw, 2003; Tate, Sibert, \& King, 1997). For example, Backlund and colleagues (2007) used a virtual-reality video game to enhance firefighter training. The authors discovered that virtual training complimented the traditional firefighter training by improving learning objectives while increasing self-motivation. Other work has used traditional firefighter training simulations to test training (Henderson, Berry, \& Matic, 2007). These simulations involved real-life tasks that may have maximized the fidelity. Virtual reality 
environment training offers a cost-effective solution to training but it should be accompanied with real-life simulation training. Kozak and colleagues (1993), describe how their real-life training group performed significantly better than the virtual reality training group. Therefore, a combination of virtual reality training and real-life training is best to increase performance and learning.

Secondary factors found in simulation can have a large impact on performance and learning. These secondary factors include feedback, quality of instruction, simulation environments, stress levels, the amount of practice, and the type of skill and affect the motor learning of a skill. By combining the secondary factors to create a better outline for methodological procedures of simulation training, researchers can aim to improve training to ultimately improve performance and learning. Although considerable research exists with clinical and medical skill training, there is a lack of research in simulation training within other fields.

\subsection{Challenge Point Framework}

The challenge point framework introduced by Guadagnoli and Lee (2004) explains how learning is intimately related to the amount of information that is available and interpretable during performance, which, in turn, depends on the nominal and functional difficulty of the task (Guadagnoli \& Lee, 2004). Nominal task difficulty refers only to the difficulty of the task and is impacted by both perceptual and motor performance requirements (Guadagnoli \& Lee, 2004). Functional task difficulty refers to how challenging the task is relative to the skill level of the individual performing the task and to the performance conditions (Guadagnoli \& Lee, 2004). This is important as it acknowledges that the characteristics of both the individual and the task difficulty

must be considered. Characteristics within this framework and the motor learning field include 
task difficulty, experience levels, practice schedules/variables, feedback, and the optimal point to challenge a participant to increase learning (Guadagnoli \& Lee, 2004). It is important to define and describe these characteristics to assist with future training. This framework provides a basis for task difficulty and performance to learning relationships which has been lacking from previous research. The framework states that a certain level of informational challenge is needed for leaners to benefit from training. This information can be from the environment, skills, internal (from the individual) and external feedback (from outside sources), and arousal levels of the individuals. Too little, too much, or the absence of information can hinder learning. A teacher must take into account the skill level of an individual and task difficulty and provide an optimal amount of information for learning to be enhanced. By increasing the informational demands through functional task difficulty, performance during practice may be impeded but learning may be enhanced (Guadagnoli \& Lee, 2004). Other manipulations of practice and retention context, or the environment where the skill is performed, can help increase or decrease learning. Environmental manipulations can impact the external and internal feedback of individuals while performing skills (Badets \& Blandin, 2012). By performing a skill in a controlled setting, a beginner may benefit from this because no external feedback from the environment is affecting performance or learning. An expert may benefit more from performing skills in an environment that causes certain levels of arousal. For example, an intermediate or advanced performer may practice skills in an environment that causes anxiety to benefit and develop their skill learning. Guadagnoli and Lee (2004) explain how an optimal challenge point is needed for different individual levels and tasks. When the amount of potential interpretable information from the task and environment is beneficial to the individual, this is described as the optimal challenge point (Guadagnoli \& Lee, 2004). With this in 
mind, the current study will utilize nominal task difficulty through complexity variations and functional task difficulty will be manipulated through testing location.

\subsubsection{Contextual Interference (CI)}

There are many ways to arrange a practice session to improve the amount of learning that takes place. One of the more common approaches is called the Contextual Interference (CI) effect (Lee \& Magill, 1983). It has been shown that random practice or unsystematic presentation of multiple and related versions of a skill leads to decrements in performance when compared to blocked or drill typed practice of a skill. However, when participants who engaged in random practice, perform a transfer test, they demonstrate improved learning compared to those who engaged in block practice (Magill \& Hall, 1990). Random practice refers to several different skills practices in a random practice order; blocked practice refers to the same skills performed several times in a row. Through increasing the contextual interference of practice schedules, through random presentation, it is hypothesized that participants are required to engage in much deeper cognitive processing when practicing a skill which leads to enhanced learning (Wulf \& Shea, 2002).

\subsection{Task Complexity}

Recent research highlights the impact that skill complexity has on motor learning (Wulf \& Shea, 2002). Defining simple and complex skills and the differences between the two in terms of learning and performance is a developing area of research. Sanli and Lee (2015) used a method for categorizing skill complexity using the challenge point framework. The authors utilized and manipulated nominal and functional task difficulty to observe the effects on practice and transfer learning (Sanli \& Lee, 2015). This study offered a basis for categorizing skill complextity. Results 
of their work exhibited that the challenge point framework did not predict the relationship between simple and complex skills but provided a starting point for describing complex skills (Sanli \&Lee, 2015). Research throughout the years has focused on simple skill learning. It was previously thought that the principles that apply to simple skills could be generalized to all skills, including complex skill, but it is evident that simple and complex skill are learned differently (Wulf \& Shea, 2002). Complex skills are much more difficult to define. The motor learning of simple skills and complex skills are typically not achieved the same way (Wulf \& Shea, 2002). Complex skill learning is of interest in this thesis because the skills to be learned are thought to be complex in nature. Various practice variables, feedback, and instruction all affect the outcome of learning both simple and complex skills. However, Wulf and Shea (2002) proposed that complex skills may benefit more from blocked practice. Wulf and colleagues (2002) reviewed studies with complex skill learning and the pattern typically shown was that random practice was detrimental to learning complex skills. Wulf and Shea (2002) also explain how observational learning is best for complex skills. Observational learning is where an individual imitates a model and self-regulates their performance and learning (Ferrari, 1996; Pollock \& Lee, 1992). Complex tasks require high memory demands that obscure the normally beneficial effects of CI (Wulf \& Shea, 2002). It is evident that further research needs to be conducted on complex skill learning to fully understand the motor learning of complex skills.

A study completed by Ollis, Button, and Fairweather (2005), manipulated task complexity when learning novel knot tying tasks. The current thesis differs by focusing on the general population and configuration systems that utilize certain knots. Ollis and colleagues (2005), had 24 firefighters and 24 college students train to learn six knots with varying complexity, that are used within the firefighting profession (Ollis et al., 2005). They established a pre-test baseline and 
utilized two transfer tests to examine learning. The transfer tests, one occluded visual feedback, and the second transfer test consisted of a novel knot tying task. The first transfer test of tying knots blindfolded was selected to reflect that firefighters have to tie knots within confined and smoke-filled/dark locations (Ollis et al., 2005). Ollis and colleagues (2005) found that practice on complex knots led to poorer performance during retention, compared to the group that practiced on the simple knots. Thus, complexity during practice is an important variable to consider when developing skill training.

Psychological factors, specifically anxiety, can also accompany complex skill learning. Anxiety reduces the benefits of random practice schedules because participants become uncomfortable with variability and unpredicted contexts (Shewokis et al., 1995). A model called the inverted-U hypothesis (Yerkes \& Dodson, 1908), explains that different complexities in tasks must have different and optimal levels of arousal and anxiety to be advantageous to performance (Eysenck, \& Calvo, 1992; Martens \& Landers, 1970). Therefore, for an individual to excel in performance the anxiety must be low for a difficult task and the anxiety must be high for easy tasks Yerkes \& Dodson, 1908). Anxiety can have major impacts on the performance and motor learning of tasks with various complexities.

\subsection{Anxiety}

According to the The Mental Health Commission of Canada (2014), anxiety disorders are one the most common mental illness in Canada with $9 \%$ of men and $16 \%$ of women affected annually. Anxiety could be used as a tool to improve performance and learning. Two types of anxiety have been defined. Trait anxiety refers to personality characteristics rather than the temporary feeling of state anxiety. Whereas state anxiety is an unpleasant emotional arousal toward threatening demands or dangers (Spielberger, 1972). The mental appraisal of a threat is a 
prerequisite for the involvement of this emotion (Lazarus, 1991). State anxiety can be further classified into cognitive or somatic anxiety (Williams et al., 2016). Cognitive anxiety is described as the psychological or mental component of anxiety. (Martens et al., 1990, Spielberger, 1980). In contrast, somatic anxiety is observed through the physiological symptoms (Martens et al., 1990), often through an increase in heart rate, respiration and perspiration (Williams et al., 2016). Cognitive anxiety mostly hinders performance, while somatic anxiety does not have as much of an effect (Zeidner, 1998). Cognitive anxiety measures include the State-Trait Anxiety Inventory (STAI) test (Spielberger 1980, 1983) or response to a simple single question using a Likert scale or perceived anxiety measure (Davey, Barratt, Butow \& Deeks, 2007). Somatic anxiety is typically measured using physiological devices like heart rate monitors (Martens et al., 1990; Zeidner, 1998).

Research surrounding anxiety and motor learning has demonstrated mixed findings. Research on task complexity and anxiety has observed detrimental and beneficial impacts on performance and learning (Calvo, Alamo, \& Ramos, 1990; Lawrence et al., 2014; Morris, Davis, \& Hutchings, 1981; Mueller, 1992; Mullen, Hardy, \& Tattersall, 2005; Shewokis et al., 1995). As previously stated, task difficuty has been shown to impact anxiety levels during skill performance (Shewokis et al., 1995). Task complexity has been shown to have a similar effect on cognitive anxiety and feelings of worry (Morris, Davis, \& Hutchings, 1981). Therefore, one might expect if participants would perform wore if they were told a task was difficult. One of the past research studies that observed the detrimental effects of task complexity on learning was completed by Calvo and colleagues (1990). They found that difficult tasks, fine tasks, trait anxiety, and cognitive state anxiety were associated with minor performance impairments (Calvo, Alamo, \& Ramos, 1990). Another study where anxiety was manipulated through the instructions given in golf putting 
tasks (Mullen, Hardy, \& Tattersall, 2005). Mullen and colleagues (2005) discovered that with high anxiety, performance was impaired. Anxiety and stress affect the learning and performance of motor skills (Mueller, 1992). While many studies have demonstrated anxiety and stress have a detrimental effect on performance (Mueller, 1992), recent research has found that practicing with anxiety can be beneficial to performance. Work by Lawrence, Cassell, Beattie, Woodman, Khan, Hardy and Gottwald (2014) discovered that when participants were already anxious in golf-putting tasks, they performed under conditions generating anxiety better than participants who were not previously introduced to anxiety. This study shows the importance of specificity of practice and how it can improve motor skill performance (Lawrence et al., 2014). Further, when researchers elicited anxiety and stress prior to training they found that after intervention self-reported stress and anxiety were higher than the control group (Hordacre et al., 2016). These results suggest that from that anxious testing conditions may effect performance but are likely not to impair learning (Calvo, Alamo, \& Ramos, 1990; Mullen, Hardy, \& Tattersall, 2005). However, these studies have not determined what type of conditions have detrimental or benefical effects on performance and learning. Future studies may benefit from the implementation of the challenge point framework (Guadagnoli \& Lee, 2004); whereby anxiety could be modified through task difficulty, environment, or expertise. Anxiety typically has a negative stigma surrounding it, but adding anxiety to a training regime could actually help performance and learning.

\subsubsection{Anxiety and Fear of Heights}

One explanation for increases in anxiety and stress during performance is a phobia. A phobia is a response to a perceived threat that is consciously recognized as dangerous (Spielberger, 2013). A phobia results in an unpleasant emotional state consisting of both psychological and physiological responses such as agitation, dread, tension, and increases in heart rate, perspiration 
and respiration. Fear and anxiety have many overlapping states that focus on threats, but are considered separate (Öhman, 2008). While the response to phobias have an identifiable stimulus, the responses to anxiety are less identifiable. Anxiety is typically a response to a phobia and is considered an emotion (Öhman, 2008). One study that describes anxiety and phobias examined the sensory and cognitive anxiety variables of acrophobia (Coelho \& Wallis, 2010). Acrophobia, is defined as the abnormal dread of being in a high place or a fear of heights, and is one of the most prevalent phobias (Coelho \& Wallis, 2010). Results show that a fear of heights can produce strong feelings of discomfort and fear in otherwise calm individuals (Coelho \& Wallis, 2010). Therefore, a fear of heights may have an impact on the motor learning of tasks. While this phobia is often observed in the general population (Coelho \& Wallis, 2010) there is a growing area of research observing the impacts of fear and anxiety on working professionals' performance and learning. Many professionals are exposed to a complex combination of stressors; including fear of death and injury and uncertainty which can accompany acrophobia (Coelho \& Wallis, 2010; Lieberman et al., 2006; Young et al., 2013). For example, while working at heights, firefighters must be calm and focused; although a fear of heights may be detrimental to their performance and endanger others (Young et al., 2013). Further research is needed to distinguish the role of anxiety on performance and learning in professionals.

\subsubsection{Anxiety in the Workplace}

Professionals can be vulnerable to anxiety and stress in a workplace environment. In particular, research from first responders shows high levels of stress and anxiety in the occupation (Brown et al., 2002; LeBlanc et al., 2005 Roy \& Steptoe, 1994; Young et al., 2013). First responders work in dangerous settings and must be able to perform under stress (Young et al., 2013). These environments can be life threatening, to both the people these professionals are 
assisting and to themselves. LeBlanc and colleagues (2005) observed stress in first responder paramedics and found high levels of stress in clinical settings can increase human errors. The profession of firefighting is very diverse and firefighters must perform a variety of skills, often in extreme environments. Some firefighting job descriptions require these professionals to work at heights, on the ground, with fires, with hazardous materials, provide medical aid, and perform rescue/recovery operations (Ollis et al., 2005). Brown and colleagues (2002) outline the stressors that firefighters experience and suggested that as a profession they are not coping effectively. Young and colleagues (2013) examined different stressors and anxiety in the fire fighting profession and observed that stress levels and percieved workload are dependent on the role of the firefighter (Young et al., 2013). A strategy that may assist with diminishing the ocupational stress is more task specific training. Given the workplace demands on firefighters it is important to ensure that training is designed to reduce anxiety while maximizing performance (Alexander et al., 1993; Young et al., 2013).

\subsection{Conclusions}

The literature surrounding motor learning describes many of the secondary factors that affect the performance and learning of skills. The current review focused on the factors related to the current research. The type, amount, and specificity of practice all have major impacts on an individual's ability to perform and learn skills. Simulation training was observed to be a strong aid in motor learning and performance. The benefits and disadvantages of training with anxiety have conflicting evidence. It is clear how anxiety impacts skill performance, although it is unclear about how anxiety affects the learning process. Skill training and professional training should incorporate a certain level of challenge; manipulation through anxieties, task difficulties, and environmental factors could lead to better skill training, better performance on the job, and better learning. 


\subsection{References}

Acrophobia (n.d.) In Merriam Webster Online. Retrieved from https://www.merriamwebster.com/dictionary/acrophobia

Adams, J. A. (1964). Motor skills. Annual Review of Psychology, 15, 181-202.

Alexander, C. N., Swanson, G. C., Rainforth, M. V., Carlisle, T. W., Todd, C. C., \& Oates Jr, R. M. (1993). Effects of the Transcendental Meditation program on stress reduction, health, and employee development: A prospective study in two occupational settings. Anxiety, Stress and Coping, 6(3), 245-262.

Arora, S., Aggarwal, R., Hull, L., Miskovic, D., Kneebone, R., Darzi, A., \& Sevdalis, N. (2011). Mental practice enhances technical skills and teamwork in crisis simulations-a double blind, randomised controlled study. Journal of the American College of Surgeons, 213(3), S126.

Backlund, P., Engstrom, H., Hammar, C., Johannesson, M., \& Lebram, M. (2007, July). Sidh-a game based firefighter training simulation. In 2007 11th International Conference Information Visualization (IV'07) (pp. 899-907). IEEE.

Badets, A., \& Blandin, Y. (2012). Feedback and intention during motor-skill learning: A connection with prospective memory. Psychological Research, 76, 601-610. https://doi.org/10.1007/s00426-011-0365-0

Baumeister, R. F., Hutton, D. G., \& Cairns, K. J. (1990). Negative effects of praise on skilled performance. Basic and Applied Social Psychology, 11(2), 131-148. 
Bradley, P. (2006). The history of simulation in medical education and possible future directions. Medical Education, 40(3), 254-262. https://doi.org/10.1111/j.1365-2929.2006.02394.x

Brouziyne, M., \& Molinaro, C. (2005). Mental imagery combined with physical practice of approach shots for golf beginners. Perceptual and Motor Skills, 101(1), 203-211.

Brown, J., Mulhern, G., \& Joseph, S. (2002). Incident-related stressors, locus of control, coping, and psychological distress among firefighters in Northern Ireland. Journal of Traumatic Stress, 15(2), 161-168. https://doi.org/10.1023/A:1014816309959

Calvo, M. G., Alamo, L., \& Ramos, P. M. (1990). Test anxiety, motor performance and learning: Attentional and somatic interference. Personality and Individual Differences, 11(1), 2938.

Coelho, C. M., \& Wallis, G. (2010). Deconstructing acrophobia: physiological and psychological precursors to developing a fear of heights. Depression and Anxiety, 27(9), 864-870.

Crossman, E. R. F. W. (1959). A theory of the acquisition of speed-skill*. Ergonomics, 2(2), 153166.1

Davey, H. M., Barratt, A. L., Butow, P. N., \& Deeks, J. J. (2007). A one-item question with a Likert or Visual Analog Scale adequately measured current anxiety. Journal of Clinical Epidemiology, 60(4), 356-360.

Ericsson, K. A., Krampe, R. T., \& Tesch-Römer, C. (1993). The role of deliberate practice in the acquisition of expert performance. Psychological Review, 100(3), 363.

Eysenck, M. W., \& Calvo, M. G. (1992). Anxiety and performance: The processing efficiency theory. Cognition \& Emotion, 6(6), 409-434. 
Feltz, D. L., \& Landers, D. M. (1983). The effects of mental practice on motor skill learning and performance: A meta-analysis. Journal of Sport Psychology, 5(1), 25-57.

Ferrari, M. (1996). Observing the observer: Self-regulation in the observational learning of motor skills. Developmental Review, 16(2), 203-240.

Guadagnoli, M. A., \& Lee, T. D. (2004). Challenge point: a framework for conceptualizing the effects of various practice conditions in motor learning. Journal of Motor Behavior, 36(2), 212-224.

Hays, R. T., \& Singer, M. J. (1989). Simulation fidelity as an organizing concept. In Simulation Fidelity in Training System Design (pp. 47-75). Springer, New York, NY.

Henderson, N. D., Berry, M. W., \& Matic, T. (2007). Field measures of strength and fitness predict firefighter performance on physically demanding tasks. Personnel Psychology, 60(2), 431-473.

Henry, F. M., \& Rogers, D. E. (1964). Increased response latency for complicated movements and the "memory drum" theory of neuromotor reaction. Research Quarterly, 31, 448-458.

Henry, F. M. (1968). Specificity vs generality in learning motor skill. Cited in Schmidt, R. A. \& Wrisberg, C. A. (2008) Preparing for the learning experience. Motor Learning and Performance: A Situation-Based Learning Approach.

Hordacre, B., Immink, M. A., Ridding, M. C., \& Hillier, S. (2016). Perceptual-motor learning benefits from increased stress and anxiety. Human Movement Science, 49, 36-46.

Jarus, Tal, \& Gutman. (2001). Effects of cognitive processes and task complexity on acquisition. The Canadian Journal of Occupational Therapy, 68(5). 
Klapp, S. (1995). Motor response programming during simple and choice reaction time: The role of practice. Journal of Experimental Psychology: Human Perception \& Performance, 21, 1015-1022.

Kneebone, R. (2009). Perspective: simulation and transformational change: the paradox of expertise. Academic Medicine, 84(7), 954-957.

Kozak, J. J., Hancock, P. A., Arthur, E. J., \& Chrysler, S. T. (1993). Transfer of training from virtual reality. Ergonomics, 36(7), 777-784.

Lawrence, G. P., Cassell, V. E., Beattie, S., Woodman, T., Khan, M. A., Hardy, L., \& Gottwald, V. M. (2014). Practice with anxiety improves performance, but only when anxious: Evidence for the specificity of practice hypothesis. Psychological Research. https://doi.org/10.1007/s00426-013-0521-9

Lazarus, R. S. (1991). Cognition and motivation in emotion. American Psychologist, 46(4), 352.

LeBlanc, V. R., MacDonald, R. D., McArthur, B., King, K., \& Lepine, T. (2005). Paramedic performance in calculating drug dosages following stressful scenarios in a human patient simulator. Prehospital Emergency Care, 9(4), 439-444. DOI.10.1080/10903120500255255

Lee, T. D., \& Magill, R. A. (1983). The locus of contextual interference in motor-skill acquisition. Journal of Experimental Psychology: Learning, Memory, and Cognition, 9(4), 730.

Lewthwaite, R., \& Wulf, G. (2012). "Motor learning through a motivational lens," in Skill Acquisition in Sport: Research, Theory and Practice, 2nd Edn, edits N. J. Hodges and A. M. Williams (London: Routlegde), 173-191. 
Lieberman, H. R., Niro, P., Tharion, W. J., Nindl, B. C., Castellani, J. W., \& Montain, S. J. (2006). Cognition during sustained operations: comparison of a laboratory simulation to field studies. Aviation, Space, and Environmental Medicine, 77(9), 929-935.

Linn, R. L., \& Burton, E. (1994). Performance-based assessment: Implications of task specificity. Educational Measurement: Issues and Practice, 13(1), 5-8.

Luft, A. R., \& Buitrago, M. M. (2005). Stages of motor skill learning. Molecular Neurobiology, 32(3), 205-216.

Magill, R. A. (2001). Motor learning: Concepts and applications (6th ed.). Madison, WI: Brown \& Benchmark.

Magill, R. A. (2004). Motor learning and control (7th ed.). New York: McGraw-Hill

Magill, R. A., \& Hall, K. G. (1990). A review of the contextual interference effect in motor skill acquisition. Human Movement Science, 9(3-5), 241-289. https://doi.org/10.1016/0167 $-9457(90) 90005-X$

Maran, N. J., \& Glavin, R. (2003). Low-to high-fidelity simulation-a continuum of medical education. Medical Education, 37(s1), 22-28.

Martens, R., \& Landers, D. M. (1970). Motor performance under stress: A test of the inverted-U hypothesis. Journal of Personality and Social Psychology, 16(1), 29.

Martens, R.,Vealy, R.S., Burton, D. (1990). Competitive Anxiety in Sport Human Kinetics, Champaign,IL. 
McGaghie, W. C., Issenberg, S. B., Petrusa, E. R., \& Scalese, R. J. (2006). Effect of practice on standardised learning outcomes in simulation-based medical education. Medical Education, 40(8), 792-797.

Mental Health Commission of Canada (2014) Retrieved from: https://www.mentalhealth commission.ca/English/annual-report-2014-2015

Minett, G. M., \& Costello, J. T. (2015). Specificity and context in post-exercise recovery: it is not a one-size-fits-all approach. Frontiers in Physiology, 6, 130.

Mook, D. G. (1983). In defense of external invalidity. American psychologist, 38(4), 379.

Mori, B., Carnahan, H., \& Herold, J. (2015). Use of simulation learning experiences in physical therapy entry-to-practice curricula: a systematic review. Physiotherapy Canada, 67(2), 194-202.

Morris, L. W., Davis, M. a, \& Hutchings, C. H. (1981). Cognitive and emotional components of anxiety: Literature review and a revised worry-emotionality scale. Journal of Educational Psychology, 73(4), 541. https://doi.org/10.1037/0022-0663.73.4.541

Mueller, J. H. (1992). Anxiety and performance. Handbook of human performance. State and Trait, 3, 127-160.

Mullen, R., Hardy, L., \& Tattersall, A. (2005). The effects of anxiety on motor performance: A test of the conscious processing hypothesis. Journal of Sport and Exercise Psychology, $27(2), 212-225$.

Newell, A., \& Rosenbloom, P. S. (1981). Mechanisms of skill acquisition and the law of practice. Cognitive Skills and their Acquisition, 1(1981), 1-55. 
National Institute of Health (2009). Competencies Proficiency Scale. Retrieved from https://hr.nih.gov/working-nih/competencies/competencies-proficiency-scale

Norman, G., Dore, K., \& Grierson, L. (2012). The minimal relationship between simulation fidelity and transfer of learning. Medical Education, 46(7), 636-647.

Öhman, A. (2008). Fear and anxiety. Emotions, 709.

Ollis, S., Button, C., \& Fairweather, M. (2005). The influence of professional expertise and task complexity upon the potency of the contextual interference effect. Acta Psychologica, $118(3), 229-244$.

Parsons, K. (2014). Human thermal environments: the effects of hot, moderate, and cold environments on human health, comfort, and performance. CRC press. $3^{\text {rd }}$ Edition

Perdigau, E., Torguet, P., Sanza, C., \& Jessel, J. P. (2003, November). A distributed virtual storytelling system for firefighters training. In International Conference on Virtual Storytelling (pp. 227-230). Springer, Berlin, Heidelberg.

Perkins, G. D. (2007). Simulation in resuscitation training. Resuscitation, 73(2), 202-211.

Pollock, B. J., \& Lee, T. D. (1992). Effects of the model's skill level on observational motor learning. Research Quarterly for Exercise and Sport, 63(1), 25-29.

Porte, M. C., Xeroulis, G., Reznick, R. K., \& Dubrowski, A. (2007). Verbal feedback from an expert is more effective than self-accessed feedback about motion efficiency in learning new surgical skills. The American Journal of Surgery, 193(1), 105-110.

Proteau, L. (1992). On the specificity of learning and the role of visual information for movement control. In Advances in Psychology, 85, 67-103. North-Holland. 
Proteau, L., Tremblay, L., \& Dejaeger, D. (1998). Practice does not diminish the role of visual information in on-line control of a precision walking task: Support for the specificity of practice hypothesis. Journal of Motor Behavior, 30(2), 143-150.

Rodriguez, B. I., Craske, M. G., Mineka, S., \& Hladek, D. (1999). Context-specificity of relapse: effects of therapist and environmental context on return of fear. Behaviour Research and Therapy, 37(9), 845-862.

Roy, M. P., \& Steptoe, A. (1994). Daily stressors and social support availability as predictors of depressed mood in male firefighters. Work and Stress, 8(3), 210-219. https://doi.org/10.1080/02678379408259993

Sanli, E. A., \& Lee, T. D. (2015). Nominal and functional task difficulty in skill acquisition: Effects on performance in two tests of transfer. Human Movement Science, 41, 218-229. https://doi.org/10.1016/j.humov.2015.03.006

Saunders, T., Driskell, J. E., Johnston, J. H., \& Salas, E. (1996). The effect of stress inoculation training on anxiety and performance. Journal of Occupational Health Psychology, 1(2), 170.

Schmidt, R. A., \& Lee, T. D. (2018). Motor learning and performance: from principles to application. Human Kinetics.

Schmidt, R. A., \& Wrisberg, C. A. (2004). Motor learning and performance. Champaign, IL: Human Kinetics. 
Schmidt, R. A., Zelaznik, H., Hawkins, B., Frank, J. S., \& Quinn Jr, J. T. (1979). Motor-output variability: a theory for the accuracy of rapid motor acts. Psychological Review, 86(5), 415.

Shams, L., \& Seitz, A. R. (2008). Benefits of multisensory learning. Trends in Cognitive Sciences, 12(11), 411-417.

Shewokis, P. A., Krane, V., Snow, J., \& Greenleaf, C. (1995). A preliminary investigation into the influence on anxiety on learning a contextual interference paradigm. Journal of Sport and Exercise Psychology, 94.

Smith, T. J. (1998, October). Context specificity in performance-the defining problem for human factors/ergonomics. In Proceedings of the Human Factors and Ergonomics Society Annual Meeting, 42(10), pp. 692-696. Sage CA: Los Angeles, CA: SAGE Publications.

Spielberger, C. D. (1971). Notes and comments trait-state anxiety and motor behavior. Journal of Motor Behavior, 3(3), 265-279. DOI: 10.1080/00222895.1971.10734907

Spielberger, C. D. (1972). Anxiety: Current trends in theory and research: I. New York, N.Y.: Academic Press.

Spielberger, C. D. (1980). Test Anxiety Inventory: Sampler Set: Manual, Test Scoring:" test Attitude Inventory": Preliminary Professional Manual. Mind Garden.

Spielberger, C. D. (1983). Manual for the State-Trait Anxiety Inventory STAI (form Y)(" selfevaluation questionnaire").

Spielberger, C. D. (Ed.). (2013). Anxiety: Current trends in theory and research. Elsevier. 
Stebbins, R. J. (1968). A comparison of the effects of physical and mental practice in learning a motor skill. Research Quarterly. American Association for Health, Physical Education and Recreation, 39(3), 714-720.

St Julien, T. U., \& Shaw, C. D. (2003, October). Firefighter command training virtual environment. In Proceedings of the 2003 conference on Diversity in computing (pp. 30-33). ACM.

Tate, D. L., Sibert, L., \& King, T. (1997, March). Virtual environments for shipboard firefighting training. In Proceedings of IEEE 1997 Annual International Symposium on Virtual Reality (pp. 61-68). IEEE.

Tremblay, L., \& Proteau, L. (1998). Specificity of practice: The case of powerlifting. Research Quarterly for Exercise and Sport, 69(3), 284-289.

Walsh, C. M., Rose, D. N., Dubrowski, A., Ling, S. C., Grierson, L. E., Backstein, D., \& Carnahan, H. (2011). Learning in the simulated setting: a comparison of expert-, peer-, and computer-assisted learning. Academic Medicine, 86(10), S12-S16.

Williams, C. K., Tremblay, L., \& Carnahan, H. (2016). It Pays to Go Off-Track: Practicing with Error-Augmenting Haptic Feedback Facilitates Learning of a Curve-Tracing Task. Frontiers in Psychology, 7.

Wrisberg, C. A., \& Liu, Z. (1991). The effect of contextual variety on the practice, retention, and transfer of an applied motor skill. Research Quarterly for Exercise and Sport, 62(4), 406412. https://doi.org/10.1080/02701367.1991.10607541

Wulf, G., \& Shea, C. H. (1999). Benefits of blocked over serial feedback on complex motor skill learning. Journal of Motor Behaviour, 31, 95-103. 
Wulf, G., \& Schmidt, R. A. (1997). Variability of practice and implicit motor learning. Journal of Experimental Psychology: Learning, Memory, and Cognition, 23(4), 987.

Yeung, E., Dubrowski, A., \& Carnahan, H. (2013). Simulation-augmented education in the rehabilitation professions: A scoping review. International Journal of Therapy and Rehabilitation, 20(5), 228-36.

Yerkes, R. M., \& Dodson, J. D. (1908). The relation of strength of stimulus to rapidity of habit formation. Journal of Comparative Neurology and Psychology, 18(5), 459-482.

Young, P. M., St, A., Gibson, C., Partington, E., Partington, S., \& Wetherell, M. (2013). Anxiety, stress, and perceived workload during the command and control of computer-simulated fire service training environments. International Journal of Emergency Services, 2(2), 119-130. https://doi.org/10.1108/IJES-10-2012-0042

Zeidner, M. (1998). Test anxiety: The state of the art. Springer Science \& Business Media. 


\section{Chapter 2: Co-Authorship Statement}

The following specifies my role in the preparation of the manuscript.

\section{Research Design}

The methodological procedures were developed based on previous research in the field of motor learning and anxiety and the need of research in this area. Discussions with Drs. Elizabeth Sanli, Linda Rohr and Heather Carnahan assisted in the refinement of the project details and aided in obtaining the ethics approval by the Memorial University Interdisciplinary Committee on Ethics in Human Research (ICEHR) board under protocol 20180703-HK.

\section{Data Collection}

The collection of the data was completed by myself, with assistance from Dr. Elizabeth Sanli and instructor, Dan LaCour.

\section{Data Analysis}

Myself with the assistance and direction from Drs. Elizabeth Sanli, Linda Rohr, and Heather Carnahan completed data analysis.

\section{Manuscript Preparation}

The manuscript was written by myself, with the editing and feedback assistance from Drs. Elizabeth Sanli, Linda Rohr and Heather Carnahan. 


\section{Chapter 3: Manuscript}

\section{Learning to Prepare Hauling Systems for Rope Rescue}

Authors: McWilliams Brenna ${ }^{1}$, Linda Rohr ${ }^{1}$, Elizabeth Sanli ${ }^{2}$, Heather Carnahan ${ }^{2}$

Institution: ${ }^{1}$ School of Human Kinetics and Recreation

Memorial University of Newfoundland

St. John's, Newfoundland, Canada, A1C 5S7

${ }^{2}$ School of Maritime Studies

Fisheries and Marine Institute

Memorial University of Newfoundland

St. John's, Newfoundland, Canada, A1C 5R3 


\subsection{Introduction}

\subsubsection{Background}

Rope rescue techniques can provide lifesaving safe and rapid extraction from hostile environments for victims and rescue crews (Brennan, 1998). A wide variety of environmental emergency situations require the use of rope rescue techniques including water, ice, confined spaces, and high-angles like towers, bridges, and tall structures. Many emergency personnel personnel, such as search and rescue and firefighters, undergo rope rescue training. From 2012 to 2015, eleven fatalities occurred, in the United States, during rope rescue training and in the line of duty (Feder, 2016). Clearly these tasks have risks that can be anxiety provoking for trainees. Our work will address the role of anxiety during the learning of these rope rescue skills.

The study of real life skills, like rope rescue, can provide insight into our understanding of motor learning. In turn, the theoretical study of motor learning can also inform industrial and emergency training protocols. Over the past half century, motor learning research has progressed substantially through elucidating the variables that affect practice and retention. Skill retention after practice is a reflection of how much learning has taken place, whereas learning is defined as a relatively permanent change in behaviour (Schmidt \& Lee, 2018 p178).

Practice is one of the most important factors that has been effectively shown to lead to improvements in motor learning, where greater amounts of practice have generally been positively related to skill improvement (Guadagnoli \& Lee, 2004; Magill, 2001; Schmidt \& Lee, 2018). Whether the learner benefits from the practice is influenced by factors such as the task, the environment, and practice characteristics.

Motor skills can be learned in applied settings as well as in simulated environments. Benefits from simulation include safety and targeted training to the learners' needs. Also, simulation allows 
for multiple controlled practice attempts, and provides a supportive and educational environment. To maximize practice and learning, it is best to provide specific training that reflects the real-world situation (Tremblay \& Proteau, 1998). Task specificity involves whether the task being practiced is similar to the task that is meant to be learned. To maximize the benefits of learning, environmental, individual, and task specific factors should be considered during practice (Lewthwaite \& Wulf, 2012).

One consideration when making practice realistic is that for certain industrial skills, a more realistic training scenario may cause anxiety, such as a firefighter training with real fire and smoke, marine safety training performed in open water, or rope rescue training taking place at height. We know very little about how practice with anxiety affects learning, but depending on certain factors, anxiety may be beneficial or detrimental. Therefore, more work is needed to better understand the role of anxiety in order to optimize the benefits and minimize any negative effects (Calvo, Alamo, \& Ramos, 1990; Lawrence et al., 2014; Morris, Davis, \& Hutchings, 1981; Mueller, 1992; Mullen, Hardy, \& Tattersall, 2005; Shewokis et al., 1995). Performance impairments have been shown when instruction and task difficulty were manipulated to increase anxiety (Calvo, Alamo, \& Ramos, 1990; Mullen, Hardy, \& Tattersall, 2005; Young et al., 2013). It was observed that anxious testing conditions may affect practice but are likely not to impair learning (Calvo, Alamo, \& Ramos, 1990). Contrasting research shows that individuals may improve practice and learning from the arousal associated with anxiety (Lawrence et al., 2014; Alexander et al., 1993; Tischler, Biberman, \& McKeage, 2002). It is evident that further research needs to be completed focusing on complex skill learning to fully understand learning in realistic settings such as industry, health care, and safety training (Brydges, Dubrowski \& Carnahan, 2007). 
There are two classifications of state anxiety; cognitive and somatic (Williams et al., 2016). Cognitive, also known as worry anxiety, is described as the mental component of anxiety that includes feelings of worry and negative thoughts (Martens et al., 1990, Spielberger, 1980). Somatic or emotionality anxiety, is reflected by physiological symptoms (Martens et al., 1990) such as, an increase in heart rate, respiration and perspiration (Williams et al., 2016). It was observed that cognitive anxiety typically hinders performance, while somatic anxiety does not have as much of an effect on performance (Zeidner, 1998). Fear and anxiety have many overlapping states that focus on threats, but are considered to be separate (Öhman, 2008). Acrophobia, which is defined as the abnormal dread of being in a high place or a fear of heights, is one of the most prevalent phobias associated with cognitive anxiety (Coelho \& Wallis, 2010).

To measure anixety, Spielberger $(1980,1983)$ pioneered the state-trait anxiety inventory (STAI) test. However, this has since been improved on by Davey and colleagues (Barratt, Butow \& Deeks, 2007) who proposed that a Likert scale or visual-analogue scale was quicker, easier, and a suitable replacement for the STAI (Davey et al., 2007).

\subsubsection{Purpose}

This study aims to address the role of anxiety during practice on learning to configure hauling systems. Cognitive anxiety was induced by manipulating task complexity and somatic anxiety was induced by requiring participants to practice at heights. Thus, the research questions were as follows:

a) How does practice on hauling systems of various complexities affect skill performance during practice and retention? 
b) How does practice on hauling system preparation at low and high heights affect skill performance during practice and retention?

c) Is anxiety during practice and retention affected when task complexity is increased?

d) Is anxiety during practice and retention affected when exposed to heights?

\subsection{Methodology}

\subsubsection{Participants}

Participants were volunteers from the general population of St. John's, Newfoundland and were considered beginners in knot-tying and hauling system preparation. Based on research conducted by Ollis and colleagues (2005), a statistical power analysis calculated in G*Power 3.1.9.2, indicated that a minimum sample of ten per group was required. During the recruitment process, participants were asked if they, "had any experience with rock climbing or rope system configuration?". If they responded yes, they were considered to have more experience than the general population and were excluded from the study. Exclusion criteria also included any neurological or physical limitations preventing the participant from climbing three flights of stairs, an extreme fear of heights, and/or if the participants was younger than 18 or older than 55 years. This reflects the typical age that a firefighter would complete this type of training. Twenty participants $(\mathrm{N}=20)$ volunteered ranging from 19 to 48 years and were randomly assigned to one of the two practice groups. Participants verbally provided self-reported demographics and inclusion criteria. Participants received a twenty dollar coffee shop gift card as incentive for their participation. All procedures were approved by the Memorial University Interdisciplinary Committee on Ethics in Human Research (ICEHR)- 20180703. 


\subsubsection{Apparatus and Materials}

Training and testing took place at the Marine Intitute's Offshore Safety and Survival Centre in Foxtrap, Newfoundland. The environment for the training and testing included a classroom and an elevated location. The elevated location consisted of a three story $(\sim 14 \mathrm{~m})$ firefighting training structure with grated stairs and flooring that was surrounded by railings.

\section{Hauling Systems}

Hauling and lowering systems are comprised of a series of knots, pulleys and devices assisting in high-angle rope rescue (Frank, 2010; Jackovics, 2019). Firefighters and rescue personnel are typically the individuals that would utilize these systems. These systems could be used for both hauling an individual up or lowering them to the ground (Frank, 2010). Our hauling systems includes single and double pulleys, carabiners, a multi-purpose device, double figure eight and prusik knots. The double figure eight knots are a very stable knot that are easy to take apart if needed. The triple-wrap prusik is bi-directional and can easily slide along the line and can be hauled on. The multi-purpose device is a high-efficiency pulley, with an integral rope-grab mechanism. This device allows it to be used as a lowering device on the main line and belay line systems and can be quickly changed over to a hauling system without reconfiguring the entire system (Frank, 2010). The complexities used were 3:1 and 5:1 (Figure 1). The 3:1 hauling system is considerd a simple system and the 5:1 is considered a complex system (Frank, 2010). The 3:1 system creates a $\mathrm{Z}$ shape with the lines and also known as a $\mathrm{Z}$-rig. To configure the systems, one must begin with a double figure-eight knot at the load. Then a prusik with a carabiner is attached to a pulley and the multi-purpose device is attached to the anchor. The pulleys in the hauling systems utilize mechanical advantage, ultimately allowing a person to lift much more than they are physically capable of lifting. For example, within the 5:1 system pulling the rope $5 \mathrm{~m}$ will raise 
the load $1 \mathrm{~m}$ or, in other terms, pulling 1 unit of tension creates 5 units of tension at the load. Many more complexities exist, although only two different complexities were incorporated in the present study due to time constraints.

\subsubsection{Dependent Variables}

Hauling system performance was evaluated by error scores and movement time (MT). To measure cognitive anxiety, a self-reported perceived anxiety visual-analogue scale (range $1-10$ ) was used, where higher anxiety is expressed as higher numbers (i.e. 10). Somatic anxiety was measured by heart rate $(\mathrm{HR})$ in beats per minute $(\mathrm{bpm})$ and heart rate variability (HRV) in milliseconds (ms) between heart beats. Increased somatic anxiety is typically expressed through increased HR and decreased HRV (Hoehn-Saric, 1998).

\section{Configuration Performance Scores}

The number of correct responses that each participant made during the testing protocols was counted and identified by one of two trained evaluators, each checklist was verified by the expert instructor. A checklist (Figure 2) was developed by the research team to determine the corrects actions and errors made by the participants during practice and retention. The participant could perform the task either correctly, with non-critical errors (e.g. the hauling system could still be used but the aesthetics were not perfect), or critical errors (e.g. the hauling system could not be used). An example of a non-critical error in the configuration would be if the knot in the prusik was not offset correctly and was in the way of the carabiner. In this scenario the hauling system will still work, but the configuration is not optimal. An example of a critical error would be if the rope was not put through the multi-purpose device correctly, this could drastically interfere with the rescue operations and could result in the rescuer and victim falling. If a participant completed each component correctly, they would receive a score of eleven. Deductions from a perfect score 
of eleven were made for non-critical errors (- 0.5 point) and critical errors (-1 point). MT was used to measure performance (Keele, 1968; Sanli \& Lee, 2015).

\section{Cognitive Anxiety}

Cognitive anxiety was examined through verbal questionning and a scoring sheet. A sheet of paper weighted with antonyms at each end, e.g. low and high was used to measure perceived anxiety (Davey et al., 2007; Young et al., 2013). The perceived anxiety measure contained a ten number Likert scale where ten indicated that the participants felt very anxious and one indicated that the participants did not feel any anxiety at all. The investigators used the perceived anxiety measure after every trial, and participants stated how they felt after each condition. Researchers used the following script while administering the perceived anxiety measure, "How do you feel after completing this trial? Please state or point to a number on the perceived anxiety scale. Ten indicates that you feel very anxious and one indicates that you do not feel any anxiety at all." The perceived anxiety measure was used as a quick and easy instrument to acquire the participants selfreported anxiety (Davey et al., 2007).

\section{Somatic anxiety}

Physiological/somatic anxiety was evaluated using a Zephyr Bioharness heart rate monitor that assessed the participants heart rate (HR) in beats per minute and heart rate variability (HRV) in milliseconds. HR and HRV have been shown to reflect anxiety (Williams et al., 2016). The BioHarness (Zephyr Technology Corporation, Annapolis, MD, US) is a wireless, physiological monitoring device that consists of an adjustable chest strap (50 g, $50 \mathrm{~mm}$ width; weight $35 \mathrm{~g}$,

80x40x15 mm) and detachable transmitter unit (Johnstone et al., 2012; Kim et al., 2015). Kim and colleagues found the Zephyr Bioharness be an accurate method of heart rate data collection. Each 
participant wore the Zephyr Bioharness during practice and retention. The HR and HRV was further analyzed at two time points; at the beginning of the trial and at one minute and thirty seconds into the trial. The overall average MT $(M=3.23 \mathrm{~min} \pm 0.15 S D)$ was divided in half, which gave an approximate time point of one minute and thirty seconds to analyze responses after the trial was half complete. To remain consistent, the same half way time point was used for both task complexities. A ten second average was used as a sampling window for calculations of each time point as a summary for the first and halfway responses to the trial. These sampling windows were used with the objective of observing changes in the somatic anxiety from the beginning of the trial to half way through the movement.

\subsubsection{Procedure}

Participants were randomly divided into two practice groups; a High practice group and a Low practice group. The Low practice group underwent training in a classroom setting and the High practice group trained at the elevated location $(\sim 14 \mathrm{~m})$ (Figure 3$)$. The practice training was performed within a group of one to four participants and retention testing was performed individually. The instruction during practice was completed by a trained expert (12 years) from the Offshore Safety and Survival Centre. The instructor utilized verbal, visual, and kinesthetic demonstrations of the hauling systems and its components. The instructor began by teaching each single component of the system to the participants and allowed them to get acquainted with the materials. The theory behind hauling systems, such as mechanical advantage, was taught to the participants and then the entire system was prepared. The first day of the study consisted of the practice of the hauling systems, which was completed at the respective locations that each participant was assigned to. Participants were given five practice attempts with feedback from the instructor after each attempt. During typical rope rescue training, students are only given one to 
two practice attempts of the hauling systems, and through pilot testing individuals typically achieved competence of the skill after three to four practice attempts. Given this, five practice attempts was deemed suitable. The participants first practiced the $3: 1$, followed by the 5:1 because 5:1 includes the 3:1 in the configuration. The first session took approximately three hours. The second session, completed five to seven days later, consisted of the retention test. For both training groups the retention tests were completed at the elevated location first and then in the classroom. For retention, participants were asked to complete each complexity of the hauling systems once in each environments (i.e. classroom and elevated location). The retention session took approximately one hour. After each trial the configuration performance scores and the MT was evaluated. During all trials the participants HR and HRV were continuously measured. After the completion of each trial (practice/retention testing) the primary investigator administered the perceived anxiety measure. A photograph of each hauling system configuration was taken after each trial to record and reviewed later as needed.

\subsubsection{Analyses}

Statistical significance was assessed at $p<.05$ throughout, and all analyses were conducted using SPSS Statistics for Windows, Version 23.0. Armonk, NY (IBM Corp, 2015). All dependent variables for practice were analyzed in separate 2 (Group; High, Low) x 2 (Complexity; 3:1, 5:1) x 5 (practice trial) mixed-design analyses of variance (ANOVA's) with repeated measures on the last two factors. The retention data for each dependant variable were analyzed in separate 2 (Group; High, Low) x 2 (Complexity; 3:1, 5:1) x 2 (testing location; Elevated, Classroom) mixed-design ANOVA's with repeated measures on the last two factors. Statistically significant ANOVA effects

were further analyzed using the Tukeys Post-hoc method for comparing means. Sphericity calculations and Greenhouse-Geiser corrections were completed when necessary. 
During practice and retention, less than $5 \%$ of the HR and HRV data collected from the Zephyr Bioharness was missing due to technological error. When this issue was observed, we checked to ensure the monitor was positioned correctly, all settings were correct and continued with collection.

\subsection{Results}

Participants, whose ages ranged from 19 to 48 years $(M=25.95 \pm 6.47 S D)$, were primarily students from Memorial University and $20 \%$ of the sample from the general population of St. John's, Newfoundland. This sample represents the typical age of a trainnee that would undergo rope rescue training. While the majority of the rope rescue trainees in real life are males, an equal sample of ten males and ten females were included.

\subsubsection{Practice Results}

\section{Performance Scores}

\section{Configuration}

Configuration performance was rated out of eleven, with a score of eleven being considered $100 \%$. There were statistically significant main effects for group $\left(F_{(1,18)}=8.72, p=.009\right)$ and complexity $\left(F_{(1,18)}=5.96, p=.025\right)$. As well as a significant interaction between group and complexity $\left(F_{(1,18)}=5.01, p=.038\right)$. Tukey HSD post hoc tests revealed significant differences between the 3:1 system performed by the High practice group, and all other trials (Figure 5). Also, significant differences between each group and both complexities were observed. Participants in the Low practice group performed superiorly to the High practice group.

There were statistically significant main effects for practice trial $\left(F_{(2.47,44.58)}=7.38, p<\right.$ .001) when configuration performance was analyzed. Tukeys HSD test revealed significant 
differences between trial one had greater errors than practice trials two, three, four and five; indicating that the participants' configuration performance scores improved (Figure 4a).

Movement Time (sec)

There was no statistically significant effect of group $\left(F_{(1,18)}=.03, p=.85\right)$ or task complexity $\left(F_{(1,18)}=1.34, p=.26\right)$ in the analysis of MT. As well, no significant interactions were found for group, complexity, or practice trial. However, there was a statistically significant main effect for practice trial $\left(F_{(2.7,48.61)}=8.83, p<.001\right)$. Mauchly's test of sphericity revealed that the assumption of sphericity had been violated, $\left(x^{2}(9)=20.52, p=.01\right)$, and degrees of freedom were corrected to Greenhouse- Geiser estimates $(\varepsilon=.67)$. Movement time decreased from practice trial one to practice trial five (Figure $4 b$ ).

\section{Anxiety Scores}

Cognitive Anxiety: Self-reported Perceived Anxiety

Higher values on the ten point perceived anxiety measure reflected greater perceived anxiety. There were no statistically significant main effects for group $\left(F_{(1,18)}=1.15, p=.29\right)$, or complexity $\left(F_{(1,18)}=2.8, p=.11\right)$. There was a significant main effect for practice trial $\left(F_{(2.24,}\right.$ 40.23) $=23.42, p<.001$ ), as well as a significant interaction between skill complexity and practice trial $\left(F_{(4,72)}=3.13, p=.02\right)$. Tukey post hoc comparison revealed that for the 3:1 system, practice trials three, four and five were significantly less anxious than practice trials one and two. For the 5:1 system, practice trials two, three, four and five had significantly less percieved anxiety than practice trial one (Figure 6).

Somatic Anxiety: Heart Rate (HR - bpm) 
When HR was analyzed, there were no statistically significant main effects for group $\left(F_{(1}\right.$, $18)=.68, p=.42)$ or complexity $\left(F_{(1,18)}=.032, p=.86\right)$. However, there was a significant main effect of practice trial $\left(F_{(4,15)}=5.82, p<.001\right)$ as well as a significant interaction for complexity and practice trial $\left(F_{(4,72)}=2.72, p=.03\right)$. Mauchly's test indicated that the assumption of sphericity had not been violated for practice trial $\left(x^{2}(9)=5.034, p=.83\right)$ and complexity by practice trial $\left(x^{2}(9)=11.25, p=.26\right)$. Therefore, sphericity assumption values were used. Tukey post hoc comparisons revealed that the HR was higher for the 3:1 system between practice trial one and the remaining trials (Figure 7). For the 5:1, practice trial four was significantly lower than all the others.

Half way through the completion of the skill, at one minute and thirty seconds, an average of the 10 second heart rate data was analyzed. There was no statistically significant main effect of group $\left(F_{(1,18)}=.97, p=.34\right)$. However there was significant main effect of complexity $\left(F_{(1,18)}=\right.$ $5.64, p=.03)$ and a main effect for practice trial $\left(F_{(4,72)}=3.44, p=.012\right)$ when HR was analyzed. Mauchly's test indicated that the assumption of sphericity had not been violated for practice trial $\left(x^{2}(9)=2.69, p=.97\right)$. Therefore, sphericity assumption ANOVA values were used. For the $3: 1$ system $(M=99.15, S E=4.39)$ participants had significantly higher HR's than when practicing the 5:1 system $(M=96.26, S E=4.05)$. Post hoc comparisons revealed the HR for practice trial one $(M=100.82 \mathrm{bpm}, S E=4.18)$ was higher than practice trial two $(M=96.93 \mathrm{bpm}, S E=4.62)$, three $(M=96.65 \mathrm{bpm}, S E=4.14)$, four $(M=96.59 \mathrm{bpm}, S E=4.33)$, and five $(M=97.53 \mathrm{bpm}, S E=$ 4.03). No significant interactions were observed for HR.

Somatic Anxiety: Heart Rate Variability (HRV - ms)

Due to technological error, HRV (ms) data was missing for one participant in the Low practice group $(\mathrm{N}=9)$. Therefore, HRV data reflected only a part of the sample. During the first 
10 seconds of the skill HRV was analyzed. There was no statistically significant main effect for group $\left(F_{(1,17)}=.004, p=.95\right)$ or complexity $\left(F_{(1,17)}<.00, p=.99\right)$. There was a statistically significant main effect for practice trial $\left(F_{(2.34,39.76)}=3.18, p=.045\right)$. Mauchly's test indicated that the assumption of sphericity had been violated for practice trial $\left(x^{2}(9)=20.72, p=.014\right)$ therefore, degrees of freedom were corrected for using Greenhouse-Geiser estimates of sphericity $(\varepsilon=.58)$. Participants HRV in practice trial one $(M=59.87 \mathrm{~ms}, S E=5.49)$ was higher than practice trials three $(M=71.59 \mathrm{~ms}, S E=6.65)$, four $(M=69.02 \mathrm{~ms}, S E=6.337)$, and five $(M=67.71 \mathrm{~ms}, S E=$ 7.21). No statistically significant interactions were observed.

At one minute and thirty seconds into the skill, an average of 10 second HRV data was analyzed. Due to the technological error, $\operatorname{HRV}(\mathrm{ms})$ data was missing for one participant from each of the two groups (High practice group $(\mathrm{N}=9)$ and the Low practice group $(\mathrm{N}=9)$ ). There were no statistically significant main effects for group $\left(F_{(1,16)}=.32, p=.58\right)$, complexity $\left(F_{(1,16)}\right.$ $=.56, p=.46)$ or practice trial $\left(F_{(4,64)}=1.40, p=.24\right)$, and no significant interactions were observed.

\subsubsection{Retention Results}

\section{Performance Scores}

\section{Configuration}

There were no statistically significant main effects for group $\left(F_{(1,18)}=.72 p=.40\right)$, complexity $\left(F_{(1,18)}=.17, p=.68\right)$ or testing location $\left(F_{(1,18)}=3.61, p=.07\right)$ and no significant interactions were found when configuration score was analyzed.

Movement Time (MT) 
There was no main effect of group $\left(F_{(1,18)}=.12, p=.73\right)$, but we observed a main effect of complexity $\left(F_{(1,18)}=15.49, p=.001\right)$, testing location $\left(F_{(1,18)}=6.82, p=.018\right)$, and an interaction between complexity and testing location $\left(F_{(1,18)}=9.727, p=.006\right)$. As seen in Figure 8c, the 3:1 complexity MT was the same for both the elevated and classroom environments. However, for the 5:1 complexity, MT was higher for the elevated location compared to the classroom environment.

\section{Anxiety scores}

\section{Cognitive Anxiety: Self-reported Perceived Anxiety}

There were no statistically significant main effects of perceived anxiety for group $\left(F_{(1,18)}\right.$ $=.67, p=.42)$ or complexity $\left(F_{(1,18)}=.09, p=.77\right)$. There was a significant main effect for testing location $\left(F_{(1,18)}=33.18, p<.001\right.$, Figure $\left.8 \mathrm{a}\right)$. Perceived anxiety was higher for both practice groups at the elevated location during retention. A significant interaction was observed between group and complexity $\left(F_{(1,18)}=9.04, p=.008\right)$. For the $3: 1$ complexity there was no difference between the practice groups. However, the Low practice group had higher perceived anxiety than the High practice group during the 5:1 complexity (refer to Figure $8 \mathrm{~b}$ )

Somatic Anxiety: Heart Rate (HR)

During the first 10 seconds of the skill, analyses showed no statistically significant main effects for group $\left(F_{(1,18)}=.89, p=.36\right)$, complexity $\left(F_{(1,18)}=1.07, p=.31\right)$ or testing location $(F$ $(1,18)=1.18, p=.29)$ for HR. However, there was a significant interaction for complexity and testing location $\left(F_{(1,18)}=5.18, p=.03\right)$. For the 3:1 complexity, HR was significantly higher during the elevated condition $(M=99.62, S E=4.53)$ compared to the classroom condition $(M=$ 
93.14, $S E=5.42$ ). For the 5:1 complexity (which was performed after the $3: 1$ complexity) there was no difference between the retention testing locations.

The average of 10 seconds of HR data was analyzed at one minute and thirty seconds. There were no statistically significant main effects for group $\left(F_{(1,18)}=3.48, p=.08\right)$, complexity $\left(F_{(1,18)}=2.22, p=.15\right)$ or testing location $\left(F_{(1,18)}=.83, p=.37\right)$. No significant interactions were observed in the variables, half way through the skill.

Somatic Anxiety: Heart Rate Variability (HRV)

Due to technological error, HRV (ms) data from four participants from each group was missing (the High practice group $(\mathrm{N}=6)$ and the Low practice group $(\mathrm{N}=6))$. During the first 10 seconds of the skill HRV was analyzed. There were no significant main effects for group $\left(F_{(1,10)}\right.$ $=1.16, p=.31)$, complexity $\left(F_{(1,10)}=3.58, p=.08\right)$ and testing location $\left(F_{(1,10)}=4.61, p=0.57\right)$. No significant interactions were observed.

Half way through the completion of the skill, at one minute and thirty seconds, an average of 10 seconds of HRV data was analyzed. Due to technological error, HRV (ms) data was missing and the group sizes are different from the other variables (where the High practice group $(\mathrm{N}=5)$ and the Low practice group $(\mathrm{N}=8))$. There were no statistically significant main effects for group $\left(F_{(1,11)}=1.31, p=.27\right)$, complexity $\left(F_{(1,11)}=1.86, p=.20\right)$ or testing location $\left(F_{(1,11)}=.10, p=\right.$ .75). No significant interactions were observed half way through the skill.

\subsection{Discussion}

In summary, participant's configuration performance during practice and retention was not affected by the complexity of the hauling system. However, performance speed was affected by hauling system complexity during retention (Figure 8). During practice, the configuration 
performance score was affected by practice trials and the practice group, but not during retention. However, MT was not affected by practice group during practice but MT was longer during retention tests, particularly during elevated retention. During practice, it was observed that complexity did not have an effect on cognitive or somatic anxiety during practice (Figure 6), but complexity had an impact on perceived anxiety during retention. When exposed to heights during practice, participants did not show significant effects on cognitive or somatic anxiety. During retention, perceived (cognitive) anxiety was highest during the elevated retention testing.

\section{Practice trial effects}

Performance (MT and configuration performance scores) and anxiety (cognitive and somatic) improved as a function of practice. This is important because it validates our dependent variables by showing that they were sensitive to practice effects (Schmidt \& Lee, 2018, p234). For example, MT decreased as a function of practice and configuration performance scores increased as a function of practice. This finding also supports the notion that participants received adequate amount of practice on the skills that led to motor learning. There were learning curve effects for configuration performance, MT and perceived anxiety during the practice trials. Significant changes from practice trial one to the final practice trial were observed, theses changes followed a typical learning curve trajectory (Crossman, 1959) and explain for increases in performance and decreases in anxiety. The improvements in performance support the notion that deliberate practice increases the performance of tasks (Ericsson, Krampe \& Tesch-Römer, 1993; Guadagnoli \& Lee, 2004). Note that HR and HRV for the first practice trial was different from the other remaining trials, which generally did not differentiate from each other. This is likely caused by greater anxiety on the first exposure but once participants had adapted to the skill, physiological responses of anxiety quickly plateaued (Brouwer, Hogervorst, Holewijn \& van Erp, 2014). 
As stated before, real-world training only requires for one to two practice attempts of each complexity and in the current study the five practice trials completed show continuous improvements in performance from practice trial one to five. Therefore, hauling system training should incorporate a minimum of five practice trials to benefit performance and learning. Further research may investigate a larger number of practice to observe whether hauling system performance and learning benefits from more than five practice trials.

\section{Height effects}

During practice an important finding was that configuration performance scores of the Low practice group were significantly better than those of the High practice group. According to the challenge point framework (Guadagnoli \& Lee, 2004), an individuals performance will suffer if the task difficulty is too high. We interpret that exposure to height increase task difficulty and reduced configuration performance.

We expected to observe influences of height on practice performance and learning (Camm, Malik, Bigger, Breithardt, Cerutti, Cohen... \& Lombardi, 1996; Cinaz, Arnrich, Marca \& Tröster, 2013). However, the only statistically significant effect of height on MT performance was during retention. It is interesting to note that practice and retention at height did not result in cognitive or somatic anxiety as expected. It is possible that while participants were performing at height ( $14 \mathrm{~m}$ ) there were enough safeguards (railings) that they may not have experienced the expected anxiety. Also, a self-declared fear of heights was an exclusion criterion for participation for this study. We chose this as an exclusion criterion because we were attempting to create a sample involving personnel criteria that would be typical search and rescue recruitment. Future work could replicate this study with individuals who have a self-declared fear of heights or personnel who are involved with search and rescue. In retention, there was an increase in MT at height but this was 
independent to the type of practice environment. Its hypothesized that the added anxiety of being in a testing situation contributed to this effect (Eysenck, 1979). In other words, there may be a subthreshold anxiety caused by working at heights, this was brought to threshold (as evidence by the significant effect of elevated perceived anxiety during retention) when performing at heights in a testing environment. Our results do not support a training specificity perspective (Tremblay \& Proteau, 1998).

\section{Task complexity effects}

During practice, there was increased perceived anxiety and decreased configuration performance scores for the simple 3:1 hauling system in comparison to the 5:1 hauling system. While this was unexpected it should be noted that the 3:1 hauling system was always practiced prior to the 5:1 hauling system. As a result, the participants may have become comfortable with the task, materials and environment by the time they performed the 5:1 (Alexander et al., 1993; Tischler, Biberman, \& McKeage, 2002; Taylor \& Asmundson, 2008). Perceived anxiety likely decreased for the 5:1 configuration because participants had increased familiarity with the practice environment and the task. This pattern was replicated with HR results during practice. Participants may have gotten more comfortable with each trial and complexity and felt more competent with their abilities (Tischler, Biberman \& McKeage, 2002), which could explain the decrease in anxiety and increase in performance scores. During retention, as expected, MT was longer for the complex 5:1 hauling system. This difference was magnified when performing the 5:1 system in an elevated environment. An increase in anxiety in the elevated location with the more complex hauling system may have led to the longer MT performance observed (Eysenck, \& Calvo, 1992). These MT results are not consistent with measures of somatic anxiety but are consistent with cognitive anxiety measures (Morris, Davis, \& Hutchings, 1981). Task complexity can negatively affect cognitive 
anxiety, which would explain why the Low practice group perceived the difficult 5:1 hauling system as producing the most anxiety (Morris, Davis, \& Hutchings, 1981).

\subsection{Perspectives}

There were limitations to our study. We did not demonstrate any direct impacts from heights on performance or anxiety. The railings and safety barriers at the elevated location may have provided the participants with enough comfort that they did not experience realistic anxiety from that setting. Self-reported perceived anxiety was administered after every trial and it is possible that this measure may have lost its sensitivity over repeated exposure. Instrumentation issues may be apparent due to daily fluctuations in technology and self-reported scores can affect the internal validity (Taylor \& Asmundson, 2008). The reliability of the Zephyr Bioharness was an issue due to the data missing for a few of the trials. The checklist utilized for the configuration performance scores has not yet been validated by experts and had a maximum of eleven items. During practice, the 3:1 complexity was practiced before the 5:1 complexity this means that some of the effects observed were from order rather than task complexity. The complexities were not counterbalance because the 3:1 must be learnt prior to the $5: 1$ since it is an addition onto the $3: 1$ system. As well in retention, all of the elevated trials were completed before the classroom trials. While this was purposeful to maximize the negative effects of performing at height it did create a potential order effect compound. Another limitation of the current study is the limited scope of our samples demographics and sample size. The participants in this study were primarily students, with only $20 \%$ from the general population. It was assumed that this sample would be similar to the real rope rescue population but perhaps a wider age range and primarily males. Suggestions for future research include creating a high testing and training environment that appears less safe, 
testing people who have self-declared phobias of height, and testing rope-rescue trainees so the results are more directly applicable to training firefighters and search and rescue.

\subsection{Conclusion}

To our knowledge, this is first studies to assess this type of firefighting (rope rescue) skills and anxiety induced by different complexities and environments. In the present study there was a relatively small sample size and the limited population demographics. Keeping this in mind, based on these results, training at height does not appear necessary for transfer to performing at height conditions and trainees need to practice the entire range of complexity. However, it is important that trainees get training on complex hauling systems because it has been shown that practicing and performing more complex hauling systems, contributes to cognitive anxiety related to performing at height. It is anticipated that these findings could benefit rope rescue training standards. The results do not support the specificity of training hypothesis in terms of height but do support the notion of practice for motor learning. 


\subsection{References}

Alexander, C. N., Swanson, G. C., Rainforth, M. V., Carlisle, T. W., Todd, C. C., \& Oates Jr, R. M. (1993). Effects of the Transcendental Meditation program on stress reduction, health, and employee development: A prospective study in two occupational settings. Anxiety, Stress and Coping, 6(3), 245-262.

Brennan, K. (1998). Rope Rescue for Firefighting. PennWell Books.

Brouwer, A. M., Hogervorst, M. A., Holewijn, M., \& van Erp, J. B. (2014). Evidence for effects of task difficulty but not learning on neurophysiological variables associated with effort. International Journal of Psychophysiology, 93(2), 242-252.

Brydges, R., Dubrowski, A., \& Carnahan, H. (2007). Attentional focus and motor learning: Applications to Health Professions Education. Bewegung und Training, 1, 15-16.

Calvo, M. G., Alamo, L., \& Ramos, P. M. (1990). Test anxiety, motor performance and learning: Attentional and somatic interference. Personality and Individual Differences, 11(1), 2938.

Camm, A. J. M. M., Malik, M., Bigger, J. T. G. B., Breithardt, G., Cerutti, S., Cohen, R., ... \& Lombardi, F. (1996). Heart rate variability: standards of measurement, physiological interpretation and clinical use. Task Force of the European Society of Cardiology and the North American Society of Pacing and Electrophysiology. Circulation, 93(5), 1043-1065.

Cinaz, B., Arnrich, B., Marca, R., \& Tröster, G. (2013). Monitoring of mental workload levels during an everyday life office-work scenario. Personal and Ubiquitous Computing, 17(2), 229-239. 
Coelho, C. M., \& Wallis, G. (2010). Deconstructing acrophobia: physiological and psychological precursors to developing a fear of heights. Depression and Anxiety, 27(9), 864-870.

Davey, H. M., Barratt, A. L., Butow, P. N., \& Deeks, J. J. (2007). A one-item question with a Likert or Visual Analog Scale adequately measured current anxiety. Journal of Clinical Epidemiology, 60(4), 356-360.

Ericsson, K. A., Krampe, R. T., \& Tesch-Römer, C. (1993). The role of deliberate practice in the acquisition of expert performance. Psychological Review, 100(3), 363.

Eysenck, M. W. (1979). Anxiety, learning, and memory: A reconceptualization. Journal of Research in Personality, 13(4), 363-385.

Eysenck, M. W., \& Calvo, M. G. (1992). Anxiety and performance: The processing efficiency theory. Cognition \& Emotion, 6(6), 409-434.

Frank, J. A. (2010). CMC Rope Rescue Manual.

Feder, C. (2016). Rope Rescue/Rappelling Training Deaths: Five Lessons. Retrieved from https://www.fireengineering.com/articles/print/volume-169/issue-4/features/roperescue-rappelling-training-deaths-five-lessons.html

Guadagnoli, M. A., \& Lee, T. D. (2004). Challenge point: a framework for conceptualizing the effects of various practice conditions in motor learning. Journal of Motor Behavior, 36(2), 212-224.

Hoehn-Saric, R. (1998). Psychic and somatic anxiety: worries, somatic symptoms and physiological changes. Acta Psychiatrica Scandinavica, 98, 32-38. 
IBM Corp. (Released 2015). IBM SPSS Statistics for Windows, Version 23.0. Armonk, NY: IBM Corp.

Jackovics, P. (2019). Analysis with applied statistics of the safety use of the rope rescue equipment. International Journal of Occupational Safety and Ergonomics, (just-accepted), 1-29.

Johnstone, J. A., Ford, P. A., Hughes, G., Watson, T., \& Garrett, A. T. (2012). Bioharness TM multivariable monitoring device. Part I: Validity. Journal of Sports Science and Medicine, 11, 400-408. Retrieved from http://www.jssm.org

Keele, S. W. (1968). Movement control in skilled motor performance. Psychological Bulletin, $70(61), 387$.

Kim, J. H. (2015). HHS Public Access, 34(6), 497-501. http://doi.org/10.1055/s-0032-1327661

Lawrence, G. P., Cassell, V. E., Beattie, S., Woodman, T., Khan, M. A., Hardy, L., \& Gottwald, V. M. (2014). Practice with anxiety improves performance, but only when anxious: Evidence for the specificity of practice hypothesis. Psychological Research. https://doi.org/10.1007/s00426-013-0521-9

Lewthwaite, R., \& Wulf, G. (2012). "Motor learning through a motivational lens," in Skill Acquisition in Sport: Research, Theory and Practice, 2nd Edn, eds N. J. Hodges and A. M. Williams (London: Routlegde), 173-191.

Magill, R. A. (2001). Motor learning: Concepts and applications (6th ed.). Madison, WI: Brown \& Benchmark.

Martens, R.,Vealy, R. S., Burton, D. (1990). Competitive Anxiety in Sport. Human Kinetics, Champaign,IL. 
Morris, L. W., Davis, M. A., \& Hutchings, C. H. (1981). Cognitive and emotional components of anxiety: Literature review and a revised worry-emotionality scale. Journal of Educational Psychology, 73(4), 541. https://doi.org/10.1037/0022-0663.73.4.541

Mueller, J. H. (1992). Anxiety and performance. Handbook of human performance. State and Trait, 3, 127-160.

Mullen, R., Hardy, L., \& Tattersall, A. (2005). The effects of anxiety on motor performance: A test of the conscious processing hypothesis. Journal of Sport and Exercise Psychology, $27(2), 212-225$.

Öhman, A. (2008). Fear and anxiety. Emotions, 709-711.

Ollis, S., Button, C., \& Fairweather, M. (2005). The influence of professional expertise and task complexity upon the potency of the contextual interference effect. Acta Psychologica, $118(3), 229-244$.

Sanli, E. A., \& Lee, T. D. (2015). Nominal and functional task difficulty in skill acquisition: Effects on performance in two tests of transfer. Human Movement Science, 41, 218-229. https://doi.org/10.1016/j.humov.2015.03.006

Schmidt, R. A., \& Lee, T. D. (2018). Motor learning and performance: from principles to application. Human Kinetics.

Spielberger, C. D. (1980). Test Anxiety Inventory: Sampler Set: Manual, Test Scoring:" test Attitude Inventory": Preliminary Professional Manual. Mind Garden.

Spielberger, C. D. (1983). Manual for the State-Trait Anxiety Inventory STAI (form Y)(" selfevaluation questionnaire"). 
Taylor, S., \& Asmundson, G. J. (2008). Internal and external validity in clinical research. Handbook of research methods in abnormal and clinical psychology. Sage Publications, Los Angeles, 23-34.

Tischler, L., Biberman, J., \& McKeage, R. (2002). Linking emotional intelligence, spirituality and workplace performance: Definitions, models and ideas for research. Journal of Managerial Psychology, 17(3), 203-218.

Tremblay, L., \& Proteau, L. (1998). Specificity of practice: The case of powerlifting. Research Quarterly for Exercise and Sport, 69(3), 284-289.

Williams, C. K., Tremblay, L., \& Carnahan, H. (2016). It Pays to Go Off-Track: Practicing with Error-Augmenting Haptic Feedback Facilitates Learning of a Curve-Tracing Task. Frontiers in Psychology, 7.

Young, P. M., St, A., Gibson, C., Partington, E., Partington, S., \& Wetherell, M. (2013). Anxiety, stress, and perceived workload during the command and control of computer-simulated fire service training environments. International Journal of Emergency Services, 2(2), 119-130. https://doi.org/10.1108/IJES-10-2012-0042

Zeidner, M. (1998). Test anxiety: The state of the art. Springer Science \& Business Media.

Zephyr Bioharness Technology Corporation, Annapolis, MD, US 


\subsection{Tables}

Table 1. A. Significant main effects and interactions for practice. B. Significant main effects and interactions for retention.

$A$.

\begin{tabular}{|c|c|c|c|}
\hline & $F$ & $d F$ & $p$ \\
\hline & \multicolumn{3}{|c|}{ Configuration Score } \\
\hline Group & 8.72 & 1,18 & .009 \\
\hline Complexity & 5.96 & 1,18 & .025 \\
\hline Group \& Complexity & 5.01 & 1,18 & .038 \\
\hline \multirow[t]{2}{*}{ Practice trial } & 7.39 & 4,72 & $<.001$ \\
\hline & \multicolumn{3}{|c|}{ Perceived Anxiety } \\
\hline Practice trial & 23.42 & $2.24,40.23$ & $<.001$ \\
\hline $\begin{array}{c}\text { Complexity \& Practice } \\
\text { trial }\end{array}$ & 3.19 & $3.05,54.82$ & 0.032 \\
\hline & \multicolumn{3}{|c|}{ Movement time } \\
\hline Practice trial & 8.83 & $2.7,48.61$ & $<.001$ \\
\hline & \multicolumn{3}{|c|}{ Heart rate $(10 \mathrm{sec})$} \\
\hline Practice trial & 5.80 & 4,15 & $<.001$ \\
\hline $\begin{array}{c}\text { Complexity \& Practice } \\
\text { trial }\end{array}$ & 2.71 & 4,72 & 0.036 \\
\hline & \multicolumn{3}{|c|}{ Heart rate $(1: 30)$} \\
\hline Practice trial & 3.44 & 4,72 & 0.012 \\
\hline Complexity & 5.64 & 1,18 & 0.029 \\
\hline & \multicolumn{3}{|c|}{ Heart rate variability $(10 \mathrm{sec})$} \\
\hline Practice trial & 3.18 & $2.34,39.76$ & 0.045 \\
\hline
\end{tabular}

B.

\begin{tabular}{|c|c|c|c|}
\hline & $\boldsymbol{F}$ & $\boldsymbol{d}$ & $\boldsymbol{p}$ \\
\hline & \multicolumn{3}{|c|}{ Perceived Anxiety } \\
\hline Location & 33.18 & 1,18 & $<.001$ \\
\hline Group \& Complexity & 9.04 & 1,18 & 0.008 \\
\hline & \multicolumn{3}{|c|}{ Movement time } \\
\hline Complexity & 15.46 & 1,18 & 0.001 \\
\hline Location & 6.82 & 1,18 & 0.018 \\
\hline Complexity \& Location & 9.72 & 1,18 & 0.006 \\
\hline Complexity \& Location & 5.18 & Heart Rate (10sec) \\
\hline
\end{tabular}


Table 2. A. Absolute data of mean and standard error values of non-significant variables during practice. $\boldsymbol{B}$. Absolute data of mean and standard error values of non-significant variables during retention.

A.

\begin{tabular}{|c|c|c|c|c|}
\hline Dependant Variable & $\begin{array}{c}\text { Independent } \\
\text { Variable }\end{array}$ & Condition & Mean & $\begin{array}{c}\text { Standard } \\
\text { error }\end{array}$ \\
\hline \multirow{4}{*}{ Perceived anxiety } & \multirow{2}{*}{ Group } & High & 3.73 & .43 \\
\hline & & Low & 3.07 & .43 \\
\hline & \multirow{2}{*}{ Complexity } & $3: 1$ & 3.60 & .38 \\
\hline & & $5: 1$ & 3.20 & .27 \\
\hline \multirow{4}{*}{ Movement time ( $\mathrm{sec}$ ) } & \multirow{2}{*}{ Group } & High & 196.62 & 13.23 \\
\hline & & Low & 193.21 & 13.23 \\
\hline & \multirow{2}{*}{ Complexity } & $3: 1$ & 189.46 & 10.45 \\
\hline & & $5: 1$ & 200.37 & 10.50 \\
\hline \multirow{4}{*}{ Heart Rate -10 sec avg (bpm) } & \multirow{2}{*}{ Group } & High & 92.05 & 5.87 \\
\hline & & Low & 98.89 & 5.87 \\
\hline & \multirow{2}{*}{ Complexity } & $3: 1$ & 95.60 & 4.40 \\
\hline & & $5: 1$ & 95.34 & 4.03 \\
\hline \multirow{2}{*}{ Heart Rate $-1: 30$ min avg (bpm) } & \multirow{2}{*}{ Group } & High & 93.60 & 5.90 \\
\hline & & Low & 101.82 & 5.90 \\
\hline \multirow{4}{*}{$\begin{array}{l}\text { Heart Rate Variability - } 10 \mathrm{sec} \text { avg } \\
\text { (ms) }\end{array}$} & \multirow{2}{*}{ Group } & High & 66.25 & 8.12 \\
\hline & & Low & 67.04 & 8.56 \\
\hline & \multirow{2}{*}{ Complexity } & $3: 1$ & 66.64 & 6.11 \\
\hline & & $5: 1$ & 66.65 & 5.89 \\
\hline \multirow{9}{*}{$\begin{array}{l}\text { Heart Rate Variability }-1: 30 \mathrm{~min} \\
\operatorname{avg}(\mathrm{ms})\end{array}$} & \multirow{2}{*}{ Group } & High & 76.93 & 10.38 \\
\hline & & Low & 68.62 & 10.38 \\
\hline & \multirow{2}{*}{ Complexity } & $3: 1$ & 71.97 & 7.31 \\
\hline & & $5: 1$ & 73.58 & 7.53 \\
\hline & \multirow{5}{*}{ Practice Trial } & 1 & 68.36 & 6.50 \\
\hline & & 2 & 72.64 & 7.13 \\
\hline & & 3 & 72.64 & 7.95 \\
\hline & & 4 & 74.04 & 8.31 \\
\hline & & 5 & 72.93 & 8.11 \\
\hline
\end{tabular}


B.

\begin{tabular}{|c|c|c|c|c|}
\hline Dependant Variable & $\begin{array}{c}\text { Independent } \\
\text { Variable }\end{array}$ & Condition & Mean & $\begin{array}{c}\text { Standard } \\
\text { error }\end{array}$ \\
\hline \multirow{6}{*}{ Configuration Score } & \multirow{2}{*}{ Group } & High & 10.65 & .08 \\
\hline & & Low & 10.75 & .08 \\
\hline & \multirow{2}{*}{ Complexity } & $3: 1$ & 10.67 & .09 \\
\hline & & $5: 1$ & 10.72 & .06 \\
\hline & \multirow{2}{*}{ Location } & Elevated & 10.58 & .09 \\
\hline & & Classroom & 10.81 & .07 \\
\hline \multirow{4}{*}{ Perceived anxiety } & \multirow{2}{*}{ Group } & High & 3.27 & .43 \\
\hline & & Low & 3.77 & .43 \\
\hline & \multirow{2}{*}{ Complexity } & $3: 1$ & 3.50 & .31 \\
\hline & & $5: 1$ & 3.55 & .32 \\
\hline \multirow{2}{*}{ Movement time ( $\mathrm{sec}$ ) } & \multirow{2}{*}{ Group } & High & 180.80 & 13.14 \\
\hline & & Low & 174.35 & 13.14 \\
\hline \multirow{6}{*}{ Heart Rate -10 sec avg (bpm) } & \multirow{2}{*}{ Group } & High & 91.21 & 6.36 \\
\hline & & Low & 99.69 & 6.36 \\
\hline & \multirow{2}{*}{ Complexity } & $3: 1$ & 96.38 & 4.67 \\
\hline & & $5: 1$ & 94.53 & 4.49 \\
\hline & \multirow{2}{*}{ Location } & Elevated & 96.91 & 4.14 \\
\hline & & Classroom & 94.01 & 5.18 \\
\hline \multirow{6}{*}{ Heart Rate - 1:30 min avg (bpm) } & \multirow{2}{*}{ Group } & High & 89.16 & 6.06 \\
\hline & & Low & 105.15 & 6.06 \\
\hline & \multirow{2}{*}{ Complexity } & $3: 1$ & 99.62 & 4.50 \\
\hline & & $5: 1$ & 94.69 & 4.68 \\
\hline & \multirow{2}{*}{ Location } & Elevated & 98.43 & 4.50 \\
\hline & & Classroom & 95.88 & 4.50 \\
\hline \multirow{6}{*}{$\begin{array}{l}\text { Heart Rate Variability - } 10 \text { sec avg } \\
(\mathrm{ms})\end{array}$} & \multirow{2}{*}{ Group } & High & 85.13 & 11.47 \\
\hline & & Low & 67.63 & 11.47 \\
\hline & \multirow{2}{*}{ Complexity } & $3: 1$ & 81.22 & 9.96 \\
\hline & & $5: 1$ & 71.53 & 6.74 \\
\hline & \multirow{2}{*}{ Location } & Elevated & 82.22 & 9.43 \\
\hline & & Classroom & 70.54 & 7.57 \\
\hline \multirow{6}{*}{$\begin{array}{l}\text { Heart Rate Variability - 1:30 min } \\
\qquad \operatorname{avg}(\mathrm{ms})\end{array}$} & \multirow{2}{*}{ Group } & High & 81.67 & 13.44 \\
\hline & & Low & 62.05 & 10.63 \\
\hline & \multirow{2}{*}{ Complexity } & $3: 1$ & 75.09 & 9.79 \\
\hline & & $5: 1$ & 68.63 & 7.88 \\
\hline & \multirow{2}{*}{ Location } & Elevated & 70.83 & 8.88 \\
\hline & & Classroom & 72.89 & 9.38 \\
\hline
\end{tabular}




\subsection{Figures}

Figure 1. Pictures of 3:1 and 5:1 hauling systems.

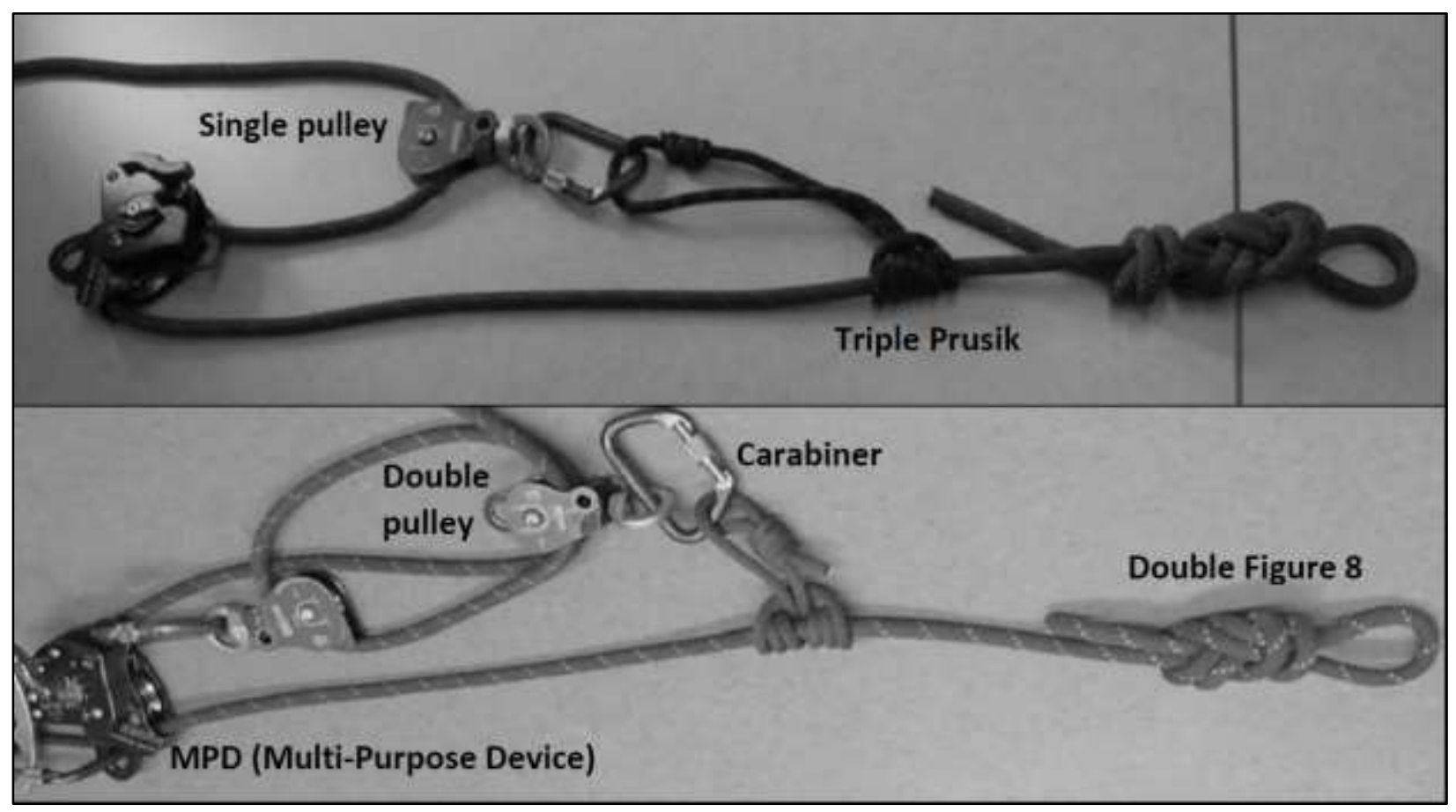


Figure 2. Example of the configuration performance score checklist for the 3:1 condition.

$\underline{3: 1}$

\begin{tabular}{|c|c|c|c|}
\hline Skill & Correct & Error (Critical) & Error (Non-Critic \\
\hline \multirow[t]{3}{*}{ Figure 8} & & & Overlapping lines \\
\hline & & & Size of loop \\
\hline & & & Long tail (2inches) \\
\hline \multirow[t]{3}{*}{ Prusik Triple wrap } & & $\begin{array}{l}\text { Missing one } \\
\text { (double) }\end{array}$ & Knot offset \\
\hline & & Looping wrong end & \multirow[t]{2}{*}{ Lines crossed } \\
\hline & & $\begin{array}{l}\text { Putting on wrong } \\
\text { line }\end{array}$ & \\
\hline \multirow[t]{3}{*}{ MPD } & & Upside down & \multirow{3}{*}{............ } \\
\hline & & Directionality & \\
\hline & & Miss a section & \\
\hline Pulleys & & Wrong Pulley & Lines crossed \\
\hline
\end{tabular}

Comments: 
Figure 3. Illustration of the procedures based on the day. Day 1 represents practice and Day 2 is the retention testing.

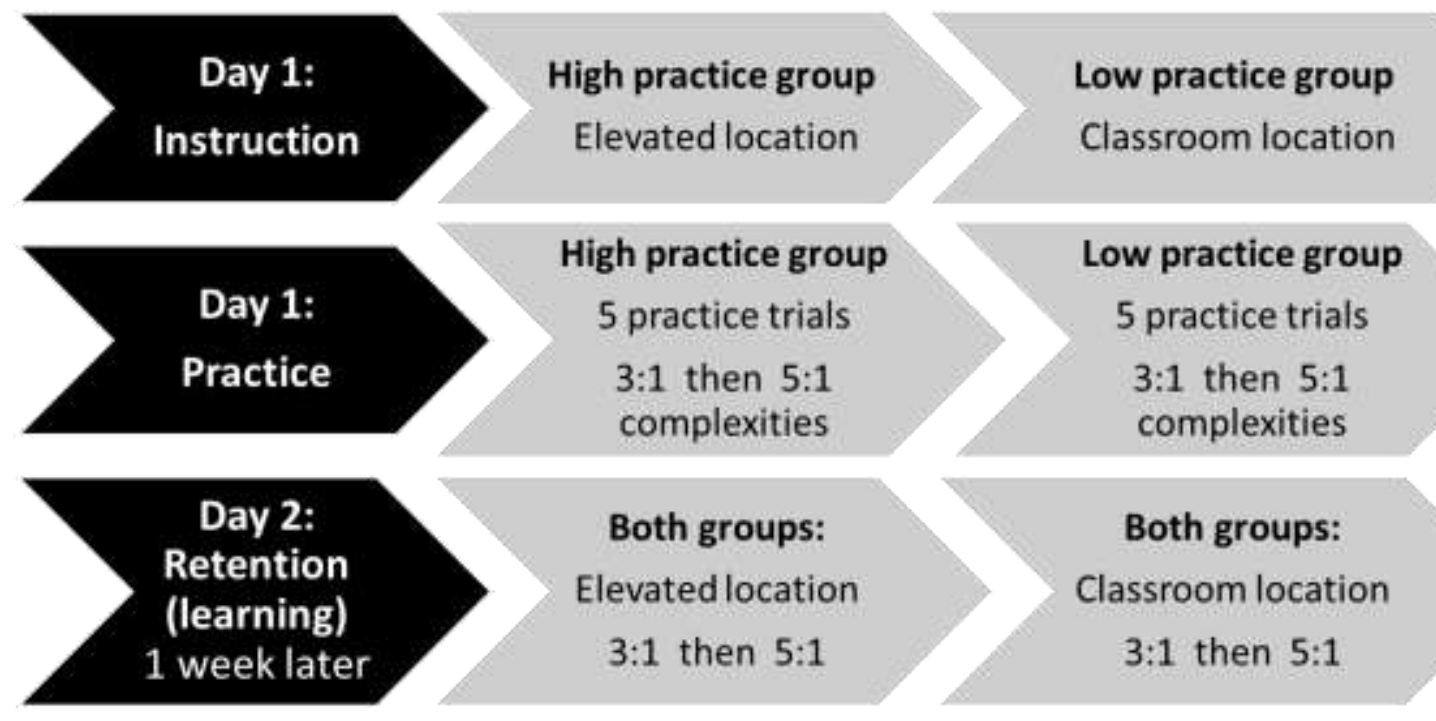


Figure 4. Significant main effects during practice. A. The average and standard errors for configuration scores of each practice trial. B. The average and standard errors for Movement Time (MT) in seconds based on practice trial.

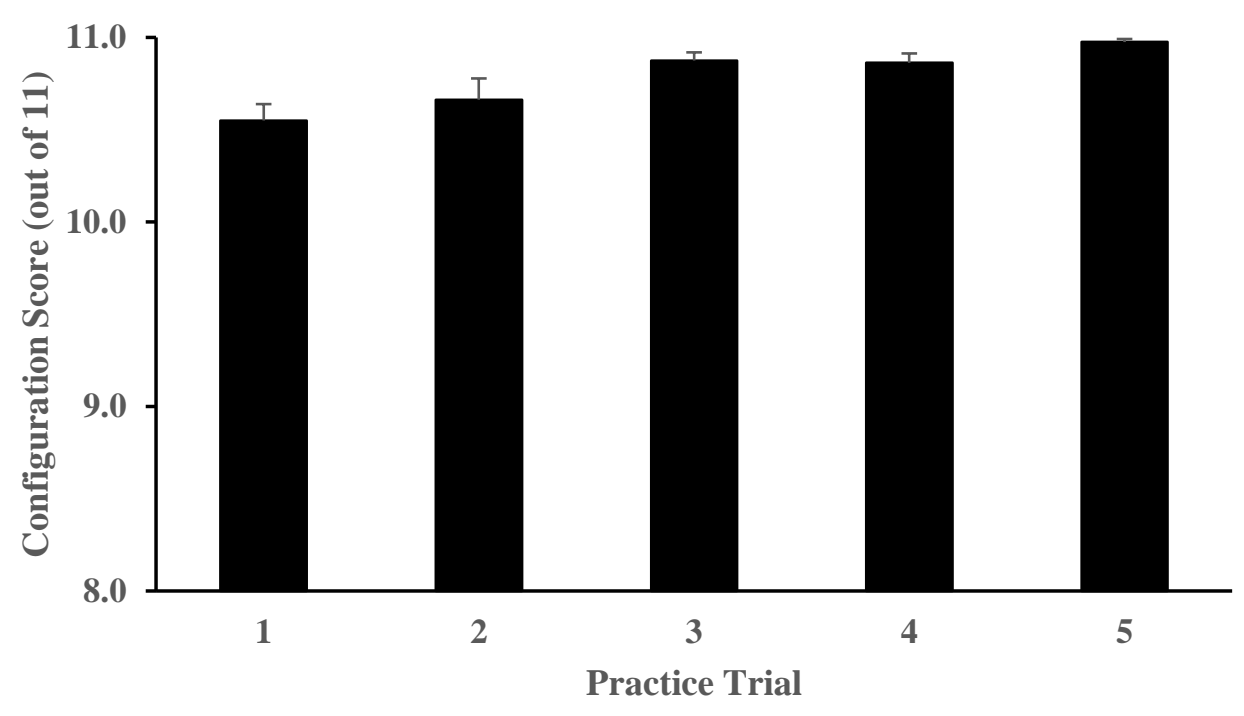

A.

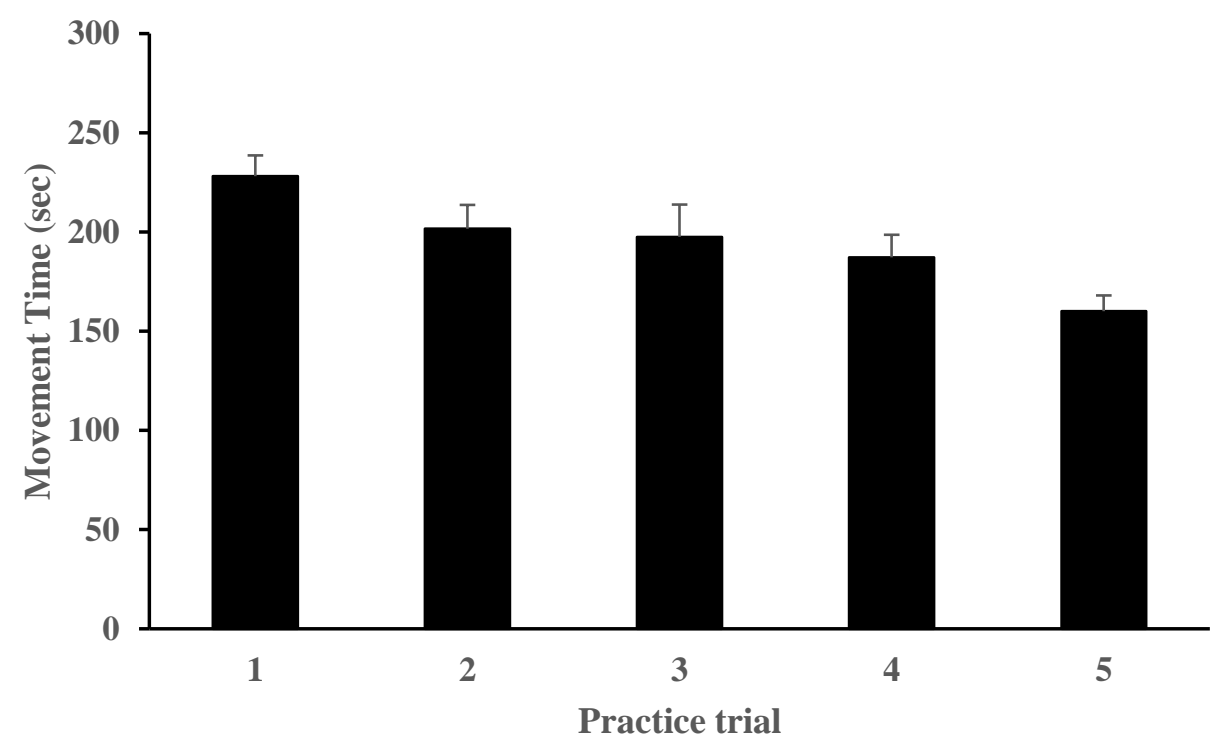

B. 
Figure 5. The significant interaction for configuration score (out of 11) between practice group and task complexity, during practice.

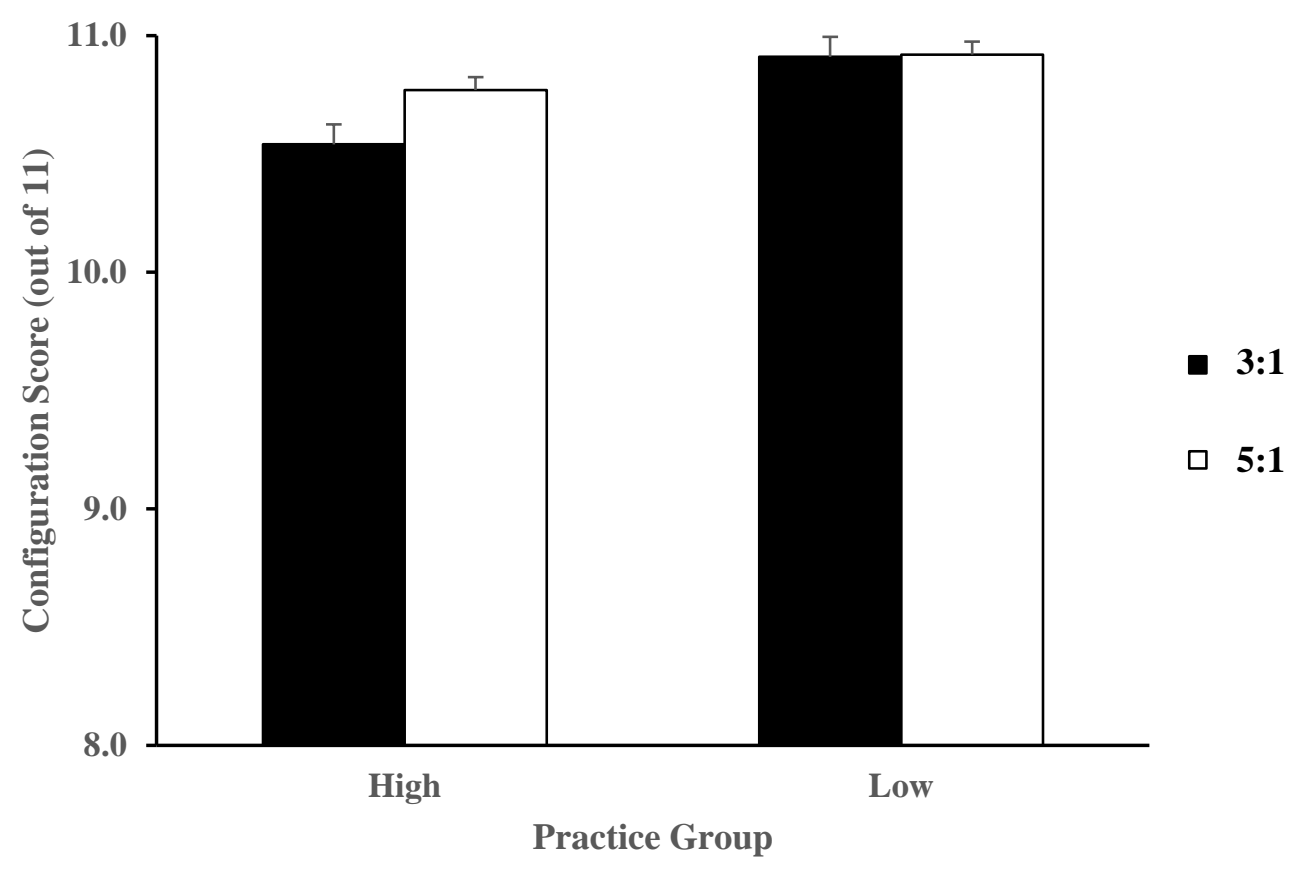


Figure 6. The perceived anxiety scores $(10=$ very anxious, $1=$ no anxiety) during each hauling system complexity and each practice trial.

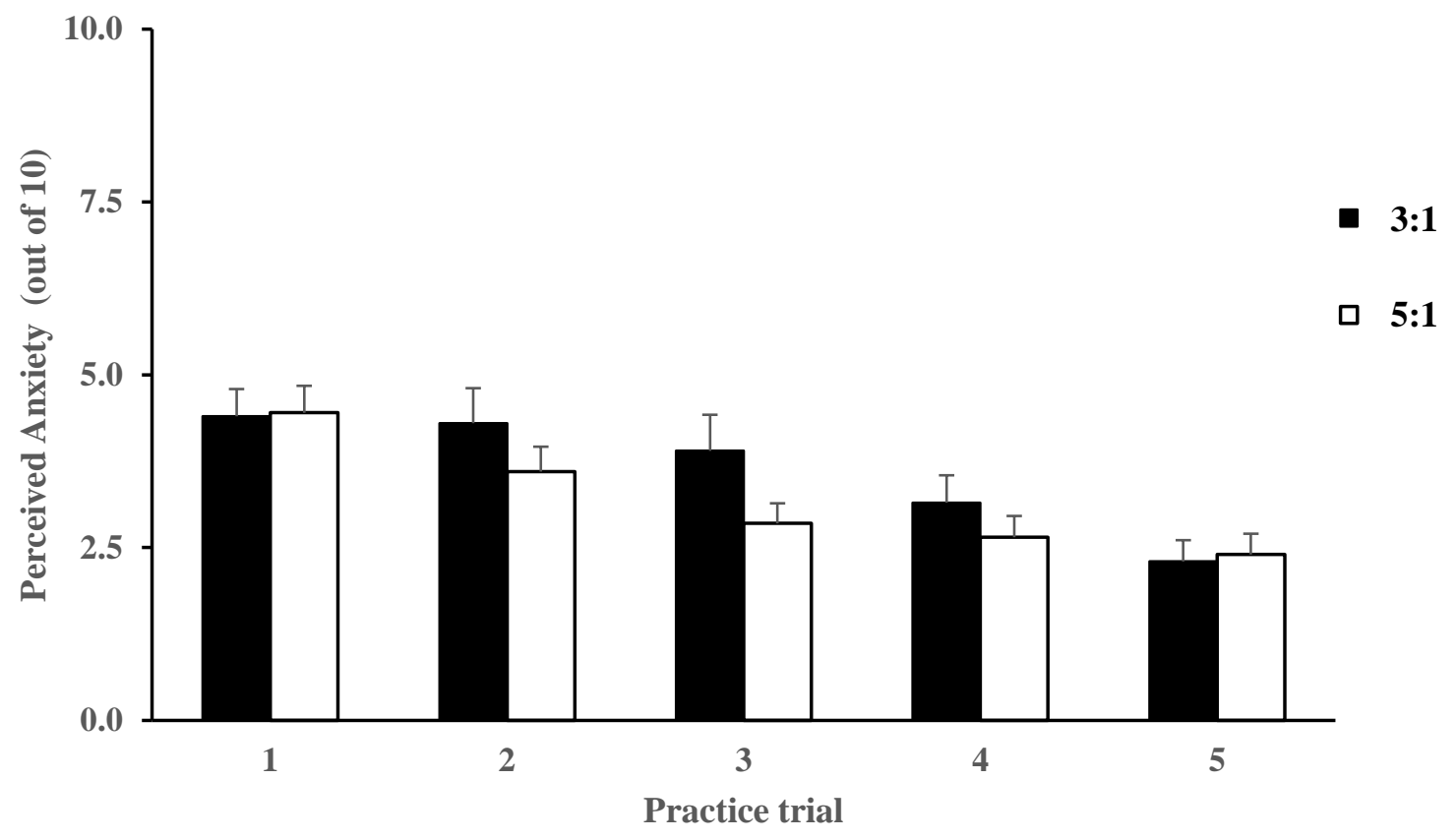


Figure 7. The average HR (at first 10sec of movement) during each hauling system complexity and each practice trial.

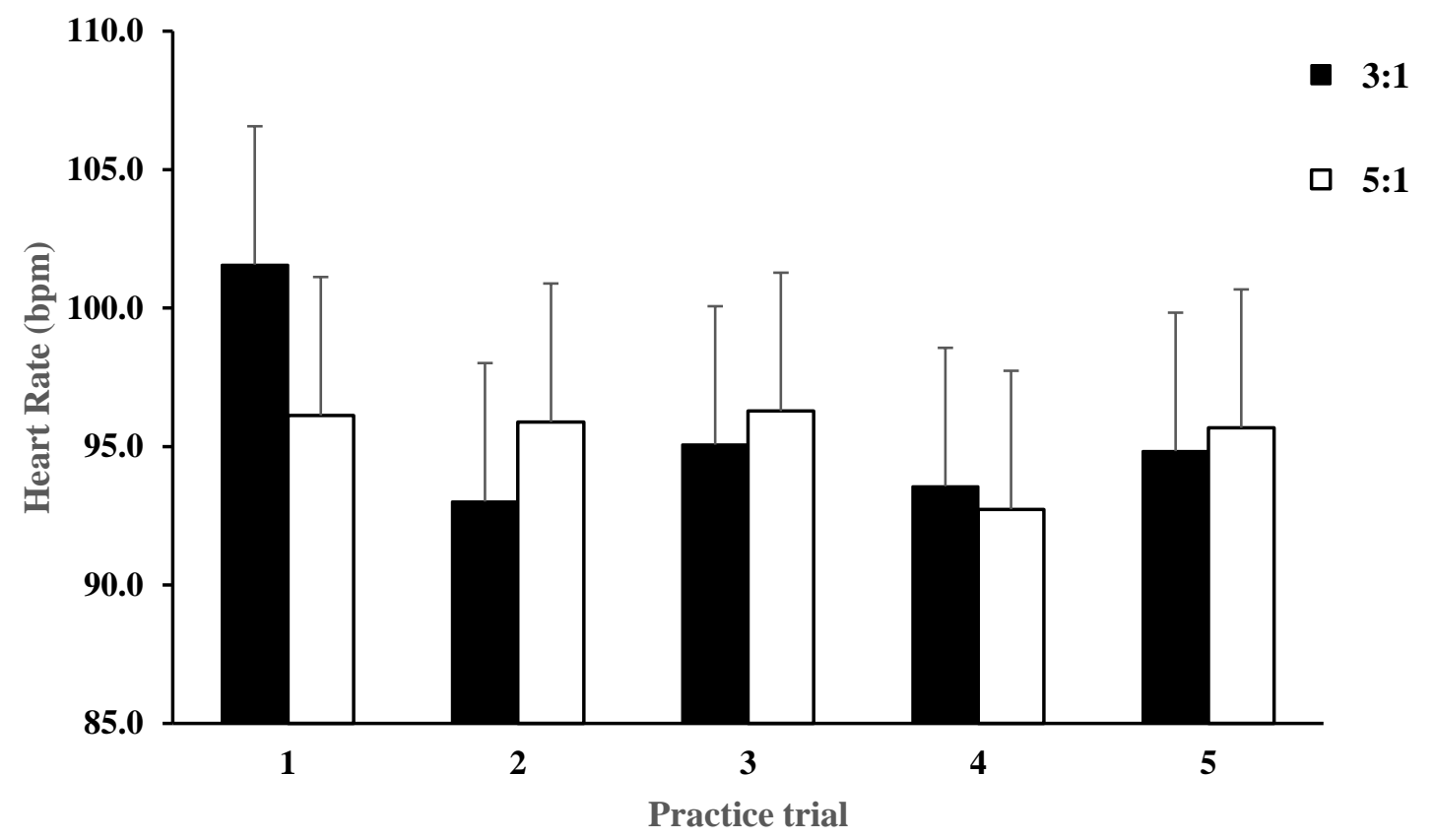


Figure 8. Significant dependant variables during retention testing. A. The average perceived anxiety levels of each retention testing location. $\boldsymbol{B}$. The perceived anxiety of each group while completing both complexities. $\boldsymbol{C}$. The Movement time (MT) (seconds) based on task complexity and location.
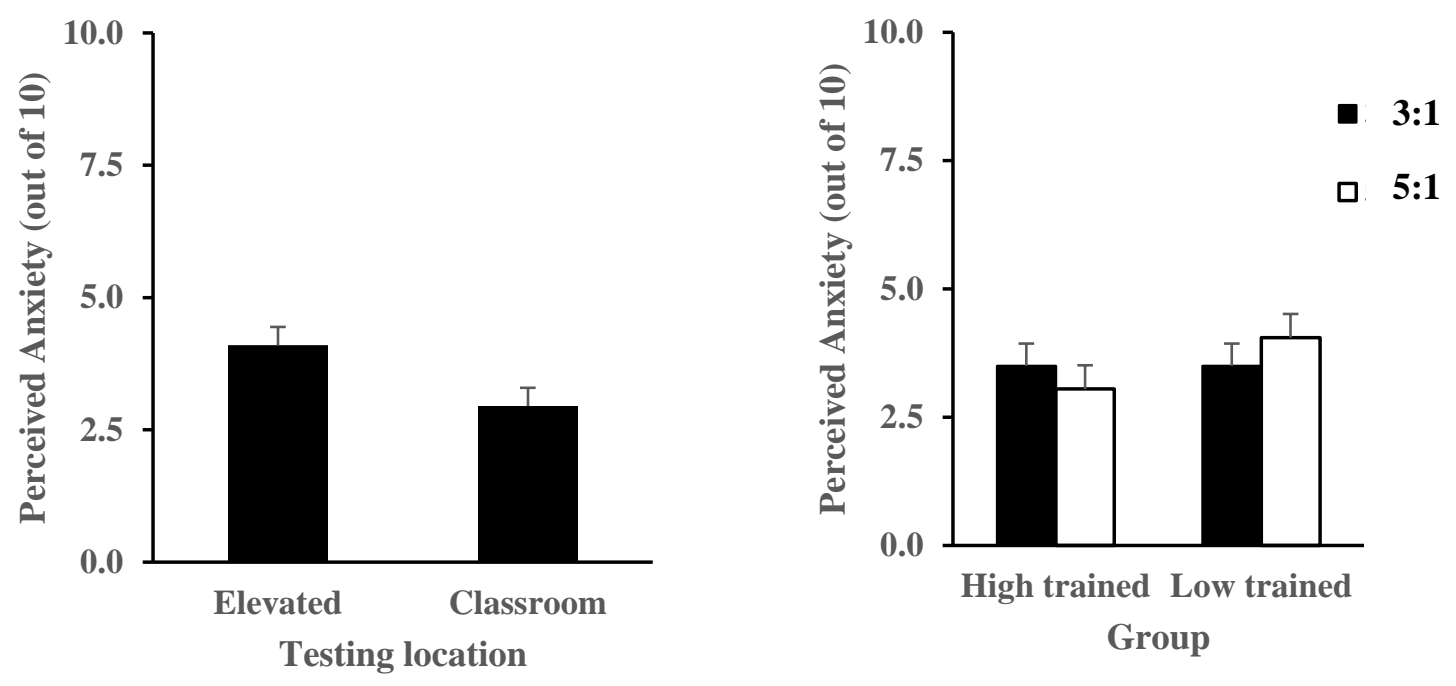

A.

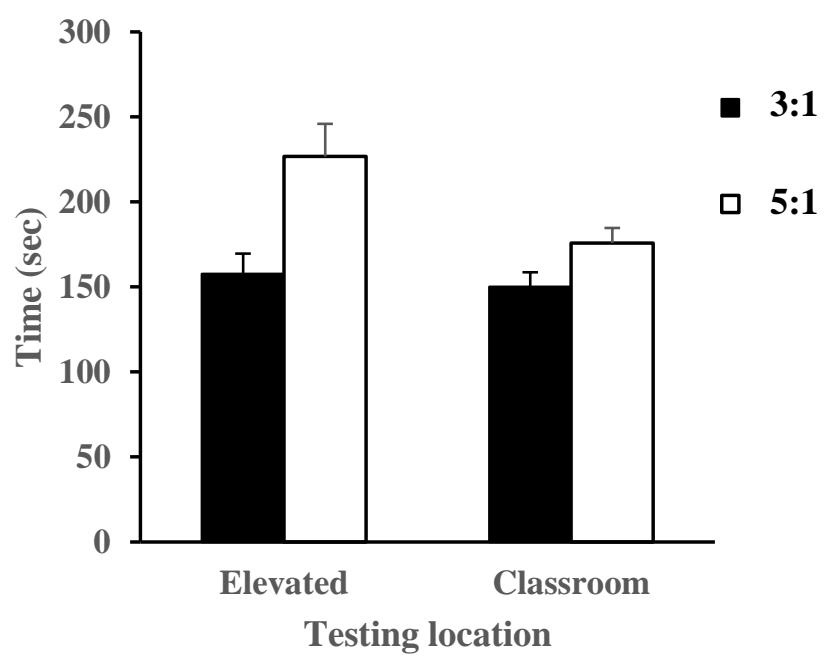

C. 